\title{
THE DENOMINATION EFFECT ON SPENDING THROUGH EXPERIMENTAL APPROACH
}

\author{
Bambang Juanda ${ }^{1}$
}

\begin{abstract}
This paper discusses the denomination effect on shopping decisions in a more realistic spending scenario with various types of goods and relatively adequate denominations, including the specimen of IDR 200,000 banknote which was being investigated, in 2015, to be printed by Bank Indonesia, and some other factors affecting spending. This research used an experimental design in a laboratory study and quasi-experimental design in a field study. In the field study, the denomination of IDR 200,000 was represented by using two pieces of the existing IDR 100,000 banknote, considered as a single IDR 200,000 banknote. Therefore, if it was used for shopping, both two banknotes of IDR 100,000 must be given to the seller even though the price of the purchased goods was below IDR 100,000.

This research showed consistent results between the laboratory and field studies, which can be summarized as follows: (1) total spending is not significantly different when using large or small denominations; (2) total expenditure is greater for consumers with low self-control; and (3) the large denomination is very influential for goods with high price, especially during unplanned shopping. This result implies the need for larger denominations for regions with high priced goods.
\end{abstract}

Keywords: denomination, spending, laboratory study, field study.

JEL Classification: C91, C93, D12, E42, E52, E58

1 Department of Economics, Faculty of Economics and Management IPB 


\section{INTRODUCTION}

Although the economic theory has largely explained the role of the amount of money, it has not yet explained, in detail, how different representations or denominations, of the same nominal, affect the spending decisions (Raghubir and Srivastava, 2009). Mishra et al. (2006) argued that the individual feels the value of money based on a single large denomination which is higher than the same nominal if represented by multiple banknotes of small denominations, resulting in relatively little spending (for one or more goods at low prices) when using money or large denominations.

Similar to the above opinion, Gourville (1998) stated that the community will make more transactions when the seller uses a marketing strategy on the consumer. The seller can make them look cheaper by framing the cost of production or the price of goods of the same nominal, in the form of small denominations. For example, promoting that the cost is only $\$ 1$ per day (Pennies-a-Day Strategy), instead of aggregate nominal of \$ 365 a year. Raghubir and Srivastava (2009) have examined the influence of the domination effecting three studies. The first study, through three surveys, (field study) concluded that the amount of spending tends to be smaller when using a single banknote of large denominations. If the large denominations are used and the spending decisions are planned, two out of the three survey results showed that the shopping is larger. The second study shows that consumers will choose money with large denominations when they need self-control in shopping. A third study shows that the denominational effects depend on individual differences in controlling spending or reducing the inconveniences of spending. Overall, it is concluded that the denominational effect occurs, because psychologically, large denominations are used as a strategic tool to control or manage the spending. In other words, individual spending decisions are influenced by denominations of the same nominal as well as other factors such as self-control and spending plan of the concerned individual.

Further research on self-control and denomination have been carried out by Baumeister (2002) as well as Hoch and Loewenstein (1991), who stated that individuals often use various efforts with the existing constraints or change incentives to control short-term behavior in order to obtain long-term benefits. Raghubir and Srivastava (2009) argued that individuals tend to spend less and prefer to receive money in large denominations than small denominations to control their spending.

The systematic influence of denominations on spending decisions has important implications in the perspective of consumer welfare as well as the perspective of monetary policy. Several studies have evaluated the influence of denominations on macro indicators such as inflation and monetary policy, for example, by Chen (1976) who only used mathematical economics or the mathematical approach of the hypothesized economic structural relationships. Such studies usually consider the level of aggregate and interdependent factors and no experimental or empirical studies have been conducted, making it difficult to explain the various causal relationships. Therefore, further research is needed in the micro scope to examine how and why the denomination affects individual decisions in terms of spending.

Further research in the micro scope explaining how and why money denominations influence spending decisions on more realistic spending scenarios 
with sufficient variety of goods and denominational representation is essential. In addition, what is the influence of the denomination of money that have not been printed yet and will review its psychological effects on spending. Denomination or banknotes with the highest nominal value in Indonesia at this time is IDR 100,000 which was first printed in 2004. With the annual inflation rate during 2004-2015 between $4 \%$ and 10\% (the highest in 2008), it is likely that Bank Indonesia will issue banknotes with larger nominal value, such as denominations of IDR 200,000.

Therefore, the present study uses a large denomination that does not exist yet i.e. a banknote of IDR 200,000. Thus, it is necessary to use an experimental study approach. The experimental design in this study used two approaches, the laboratory and field studies. In the field study, a fractional IDR 200,000 is represented by using two IDR 100,000 denominations considered as a single banknote. Thus, if used for shopping, the two banknotes should be given to the seller even if the price is below IDR 100,000.

Specifically, this paper aims to assess the determinant of on shopping behavior. This includes currency denominations, goods price, consumer selfcontrol, spending plan, consumer needs, market type or place of purchase, occupation, income, education, and residence of consumers. Furthermore, this paper will also formulate the policy implications related to the proposed IDR 200,000 denomination. We use two experimental designs i.e. laboratory study and field study. In contrast to previous studies, the present study was conducted with denominations and types of goods that are quite representative. Indeed, the respondents could buy anything at the minimarket and traditional markets in the field of study.

The next section of this paper outline the theory and related empirical studies. Section three discusses the methodology and the setting of experimental design. Section four provide result of the experiment and its analysis, while section five provide conclusion and policy recommendation.

\section{THEORY}

The research on the denominational influence on shopping behavior has been limited, so far, to one or several goods, as Raghubir and Srivastava (2009) have carried out in research to assess the influence of denominations. Shopping behavior, in addition to being influenced by denominations, can also be influenced by other factors, such as income (Henderson and Quandt, 1980; Blanchard, 2009; Sumarwan, 2014), prices (Henderson and Quandt, 1980), education (Sumarwan, 2014), planning (Raghubir and Srivastava, 2009; Mishra et al., 2006; Baumeister, 2002; Hoch and Loewenstein, 1991), and self-control (Raghubir and Srivastava, 2009). Furthermore, Sumarwan (2014) stated that in making purchasing action, consumers are influenced by individual difference factors (needs and motivation, decision, self-concept, information processing and perception, learning process, knowledge, attitude, and religion), environmental influence (demographics, social and economic, family and household, reference group, consumer situation, and technology), and decision-making process.

Research on denominational effects has been done using the existing denominations, as in Raghubir and Srivastava (2009) study using small 
denominations (4 coins of \$ 0.25) and large denominations (a 1 \$ banknote) to buy sweets in the university cafeterias. In other surveys, they use 3 denominations (5 banknotes of $\$ 1,5$ coins of $\$ 1$, and a $\$ 5$ banknote) with a nominal of $\$ 5$ that was given to the driver who stops at a gas station to spend in the existing minimarket at the gas station. In this simple experiment, which is not associated with the price of the goods, it was concluded that the chances of spending are smaller when using a single large banknote, and the will be higher if the spending decision is planned.

The experimental study approach is an effective data collection method for assessing causal relationships among variables. The use of the experimental design allows the researcher to change the values of a variable or the studied factor, but retain the values of other factors so that the influence of the studied factors can be clearly identified (Juanda, 2009). Associated with the economic studies, Juanda (2012) stated that economists often refer to it as experimental economics which is the economics of the study method applying experimental design using experimental actors whose decisions are motivated to obtain rewards so that other factors can be controlled. This experimental economy is to test various economic theories, develop economic theory, examine an economic policy (which has been or before it is implemented), and the process of economic learning.

Experimental methods, in economics, are very good ways to get better quality data (and lower costs) than the existing data (from surveys or secondary data) to observe causal relationships. At a minimum, the experimental method provides an alternative way to get the data needed to solve the problem of economic research (Juanda, 2017). One study of an economic policy before it is implemented, using an experimental approach, is a study conducted by Juanda et al. (2017) and Pambudi et al. (2014) on the determinants of a successful currency redenomination.

\section{METHODOLOGY}

Economists have developed various concepts of thought and analysis to examine economic phenomena. One of the theories that led to the revolution in the development of economic theory is the induced-value theory developed by Smith (1976). In controlling the environment (one of the basic principles of experimental design that makes better than survey design) to make other factors equal or ceteris paribus, this theory uses appropriate reward media aimed at generating certain characteristics of economic actors, so that innate characteristics become no longer influential. Therefore, the experimental design in economics, which uses this induced-value theory, can produce true or valid conclusions in the study of causal relationships.

There are three sufficient conditions to elicit the basic characteristics of the subject: monotonicity (the subject always likes greater rewards), salience (the reward received by the subject depends on the actions of the subject in the experiments according to the rules of the institution they understand) and dominance (the dominance of experimental actors' interests in experimental execution i.e. they prefer the reward to be received from their decision in the experiment). The experimental environment in the economic assessment is a controlled environment, and the subject will behave or make decisions in such a way as to earn high rewards, as explained in the experimental instructions. This 
trial instruction consists of a description of the experimental conditions, choices, and actions that the subject must perform and the reward rule that depends on the actions of the subject. The decision taken by the subject is written in the decision sheet of the subject.

Economic research through the experimental method using induced-value theory in laboratory study generally uses students as the subjects. The selection of students as experimental actors is because: (1) they are readiest to enter into experimental groups; (2) opportunity costs; (3) backgrounds from campus where most researchers appear; and (4) can reduce external influences that can be a buffer variable in the causal impact research because it requires the homogeneity of the subject (Juanda, 2009; Juanda, 2012).

The experimental design, in the present research, applied both laboratory and field studies. There were four main factors studied in the laboratory: denominations (F1); goods prices (F2); consumer self-control (F3); and consumer planning (F4). Similarly, in the field study, there were 4 main factors studied, namely: denomination (F1); the price of goods (F2), consumer expenditure planning (F4); and market types (F5). The experimental instructions and decisions, in this experimental study, can be seen in Juanda (2015).

For the field study, the subject was the respondent representing the various types of consumers in Indonesia according to the target consumers of this denominational effect study. Therefore, the congenital characteristics of the respondent (the level of needs, occupation, income, education, and residence) that may affect spending are also analyzed. These five characteristic variables are referred to as covariates, which may affect the response, although not the factor or treatment given in this experiment. While the type of market or place of consumer spending (minimarkets and traditional markets) is considered as a factor or treatment that can affect spending and its effect was analyzed.

\subsection{Experimental Design for the Laboratory Study}

In laboratory study, we implement the basic principle of experiment design, ie. how to maintain the other factors equal or cateris paribus, within the framework of induced-value theory. In this experiment, the subject always sees the incentive (reward) he will gain when making a decision, which in this case is shopping or not shopping (saving).

The experimental design in the laboratory study used a Factorial Complete Random Design (FCRD) with 4 factors as follows:

$$
\begin{aligned}
& \mathrm{Y}_{\mathrm{ijklm}}=\mu+\alpha_{\mathrm{i}}+\beta_{\mathrm{j}}+\gamma_{\mathrm{k}}+\delta_{1}+(\alpha \beta)_{\mathrm{ij}}+(\alpha \gamma)_{\mathrm{ik}}+(\alpha \delta)_{\mathrm{il}}+(\beta \gamma)_{\mathrm{jk}}+(\beta \delta)_{\mathrm{j} 1}+(\gamma \delta)_{\mathrm{kl}}+(\alpha \beta \gamma)_{\mathrm{ijk}}+ \\
& (\alpha \beta \delta)_{\mathrm{ijl}}+(\beta \gamma \delta)_{\mathrm{jkl}}+(\alpha \beta \gamma \delta)_{\mathrm{ijkl}}+\omega\left(\mathrm{Keb}_{\mathrm{ijkl}}-\overline{\mathrm{Keb}}\right)+\varepsilon_{\mathrm{ijkl}} .
\end{aligned}
$$

$Y_{\text {ijklm }}$

$\mu$
: Individual spending with k-th level of self control, l-th spending plan, price of good $\mathrm{j}$, denomination $\mathrm{i}$, and $\mathrm{m}$-th experiment replication. : Average $\mathrm{Y}$ in general (regardless of the 4 factors) 
$\alpha_{\mathrm{i}} \quad:$ The influence of $\mathrm{i}$-th denomination, $(\mathrm{i}=1$ for small denominations $\mathrm{i}=$ 2 for large denominations)

$\beta_{j} \quad$ : Influence of the price of the $j$-th good, $(j=1$ for the low price, $j=2$ for the high price)

$\gamma_{\mathrm{k}} \quad:$ Effect of the degree of self-control k-th, $(\mathrm{k}=1$ low, $\mathrm{k}=2$ high $)$

$\delta \quad$ : Influence of expenditure planning level l-th, $(1=1$ do not have; $1=2$ have)

$(\alpha \beta)_{\mathrm{ij}} \quad$ : The effect of interaction between the $\mathrm{i}$-th denomination and the price of the $j$-th good (The influence of denomination on shopping conditional to the price of the goods).

$(\alpha \gamma)_{\mathrm{ik}} \quad:$ The influence of the interaction between the i-th denomination and the k-th self-control (The effect of the denomination on the expenditure conditional to self-control of individual/community).

$(\alpha \delta)_{\mathrm{il}} \quad$ : The influence of the interaction between the i-th denomination and 1-th level of expenditure planning (The effect of the denomination on expenditure conditional to the level planning of the individual/ community expenditure).

$(\beta \gamma)_{\mathrm{jk}} \quad$ : The effect of interaction between the price of the $\mathrm{j}$-th good and the k-th self-control (The influence of price on the spending conditional to the self-control of the individual/community).

$(\beta \delta)_{j 1} \quad$ : The influence of the interaction between the $\mathrm{j}$-th price and the l-th level of expenditure planning (The influence of price on the expenditure depends on level expenditure planning i.e. individual/community).

$(\gamma \delta)_{\mathrm{kl}} \quad$ : The influence of the interaction between the k-th self-control and the l-th level of expenditure planning (The influence of self-control on spending conditional to the level of individual/community expenditure planning).

$(\alpha \beta \gamma)_{\mathrm{ijk}} \quad$ : The effect of the interaction between the i-th denomination and the $\mathrm{j}$-th price of the goods and the k-th self-control (The influence of denomination on spending conditional to the price of goods and the individual's self-control).

$(\alpha \beta \delta)_{\mathrm{ijl}} \quad$ : The influence of the interaction between the i-th denomination and the $\mathrm{j}$-th price of goods and the 1-th level expenditure planning (The influence of denomination on spending conditional to the price of goods and the level of individual/community expenditure planning).

$(\beta \gamma \delta)_{j k l} \quad$ : The influence of the interaction between the $j$-th price of goods, the self-control, and k-th level of expenditure planning (The influence of good prices on expenditure conditional to self-control and level of individual/community expenditure planning).

$(\alpha \beta \gamma \delta)_{\mathrm{ijkl}}$ : The influence of the interaction between the i-th denomination and j-th price of goods, the k-th self-control, and the level of the 1-th expenditure planning (The denominational effect on spending 
conditional to the price of goods, self-control, and the level of individual/community expenditure planning).

$\varepsilon_{\mathrm{ijk} k} \quad:$ Error for individual spending with k-th level of self control, 1-th spending plan, price of good $\mathrm{j}$, using denomination $\mathrm{i}$.

In addition to the above four main factors, the present analysis also examines the characteristics of respondents that can influence the behavior of the shopping, which is whether to buy goods because of the needs (1) or just trial (0), which is symbolized by:

$\omega\left(\mathrm{Keb}_{\mathrm{ijkl}}-\overline{\mathrm{Keb}}\right)$ : The influence of the level of needs on the individual/community expenditure with the level of the $\mathrm{k}$-th self-control and the level of the l-th expenditure planning for the $\mathrm{j}$-th good price using the i-th denomination, which is corrected with the average level of respondent's overall needs.

The response variable $(\mathrm{Y})$ is the amount of expenditure and also the savings/ investment of the IDR 200,000 received. The analysis focuses only on spending since spending and saving are two sides of the same coin. There are 4 (four) factors or variables hypothesized affecting the spending decision and studied in this laboratory study, namely:

1. The denominational factor (F1) consists of 2 levels of treatments as follows:

Level 1 : Small denominations $\left(\mathrm{K}_{1}\right)$ with details as follows:

(1 banknote of IDR 50,000) + (3 banknotes of IDR 20,000)

$+(6$ banknotes of IDR 10,000) + (6 banknotes of IDR 5,000)

Level 2 : Large denominations $\left(B_{1}\right)$ consisting of 1 banknote of IDR 200,000

Hypothesis : Shopping with small denominations tends to be higher than that of the large denominations.

2. Prices of goods (F2) consist of 2 treatment levels as follows:

Level 1 : Low prices of goods $\left(R_{2}\right)$ i.e. goods that cost a maximum of IDR 50,000 . In laboratory study activities, low priced goods provided include food (IDR 15,000), headset (IDR 25,000), umbrella (IDR 40,000), sandals (IDR 45,000), and clothes (IDR 50,000).

Level 2 : High prices of goods $\left(\mathrm{T}_{2}\right)$ i.e. goods that cost more than IDR 100,000 , consisting of bags (IDR 120,000), shoes (IDR 150,000), and jacket (IDR 190,000).

Hypothesis : Large denominational purchases (IDR 200,000) will be bigger for high priced goods, compared to low-priced goods.

3. Level of self-control (F3) consists of 2 levels of treatments as follows:

Level 1 : Low level of self-control $\left(R_{3}\right)$, where the subject will get information that if there is money left (not spent) he will get a Return on Investment (ROI) of $1.5 \%$ from the remaining money that is not spent.

Level 2 : High level of self-control $\left(\mathrm{T}_{3}\right)$, where the subject will get information that if there is money left (not spent), he will get a 
Return on Investment (ROI) of $2.5 \%$ from the remaining money (that is not spent).

Hypothesis : People with low self-control tend to have high shopping level.

4. Expenditure planning (F4) consists of 2 levels of treatments as follows:

Level 1 : Without planning (N4), where the subject can immediately spend part/all the given money, or not spend at all or the money is saved for future use or saving.

Level 2 : With planning (P4), where the enumerator provides information on the list of goods (and unit price estimates) that can be purchased, then the subject is required to make a purchase plan by filling (on the decision sheet provided), what goods will be purchased. The subject can plan to spend some/all the given money, or not spend at all or the money is saved for future use or saving. Subject must purchase goods that have been written on the decision sheet but are allowed to buy goods that have not been written as well (not planned).

Hypothesis : Large denominational spending (IDR 200,000) will be greater when the expenditure is planned compared to when it is not planned.

This RALF uses 4 factors, each factor consisting of 2 levels. Thus, there are $2 \times 2 \times 2 \times 2=16$ treatment combinations (treatments). To minimize the experimental bias, this study was replicated 5 times, so, a total of 80 experiments were conducted. Each of the 80 experiments was applied to a group of experimental actors consisting of 3 people. Therefore, the total of respondents involved in experimental activities of this laboratory study was $80 \times 3=240$ students. Determination of treatment combinations for each experimental actor was carried out randomly.

To examine whether the influence of denominations (and 3 other factors) on spending is statistically significant or not, and to examine the effect of interactions between these factors, or, in another sense, whether denominational influences are dependent on other factors, an analysis of covariance (Analysis of Covariance, or ANCOVA) was used. The ANCOVA is an analytical technique that combines analysis of variance (ANOVA) with the regression analysis to improve the accuracy of an experiment (Neter et al., 1996).

As mentioned earlier in this laboratory study, there are 16 combinations of treatments. Therefore, 16 kinds of instruction (technical instructions) of the experiment, which can be seen in Juanda (2015), will be used so that the subject understands the experiments to perform. Each of these experimental instructions has been tested prior to the actual experiment.

In the design of the experiment in laboratory study, related to the price factor of goods (F2), there are respondents (120 students) who are requested to buy only goods with maximum price of IDR 50,000 (low price), and there are also respondents that are requested to (120 students) goods that cost more than IDR 100,000 (high price). The stipulation of high-priced thresholds is adjusted to the largest denomination that already exists today, which is IDR 100,000. If the price determination is more than IDR 50,000, then it can still be bought by the existing 
denominations. The determination of the price selection of goods purchased for each experimental actor was done randomly.

For expenditure planning factors (F4), some respondents (120 students) were asked to make the planning first (what items will be purchased), and the remaining 120 respondents were not asked to make the planning first. The determination of planning characteristics for each experimental actor was carried out randomly.

The application of induced-value theory in this experiment is as follows. Respondents will get rewards in the form of incentives for each decision that they took. The incentives are the level of satisfaction from the goods they buy and the benefits of the remaining money that is not spent. So, each subject will take these incentives into account when making a spending decision (or saving).

The consumers will know the level of satisfaction after buying (and using/ consuming) the goods, with three possible satisfaction, namely: very satisfied; quite satisfied; and less satisfied. These three levels of customer satisfaction, in this experiment, are represented by a consumer surplus (SK) or the difference between maximum price he or she is willing to spend, with the transaction price. For simplification, the possible consumer surplus category obtained by consumers is $3 \%$ of the price of the goods (if very satisfied), $1.5 \%$ of the price of the goods (if fairly satisfied), and $0 \%$ of the price of the goods (if less satisfied). The determination of consumer surplus is done randomly after the consumer obtains the goods (which are exhibited in the laboratory setting).

In reality, the rest of the money that is not spent can be used later, for savings, investments, or purchases of the same or different goods with better quality and unit value. The amount of the remaining benefits of money that is not spent can describe the level of consumer self-control (F3). The greater the benefits of the remaining money that is not spent, the higher the consumer's self-control in shopping or the less spending. The actual decision of participant may differ from the characteristic assigned to them. Prior the experiment, the self-control characteristics for each experimental actor was carried out randomly.

The benefit of the spare money, in this experiment, is represented by Return on Investment (ROI). Respondents with high self-control level will get $2.5 \%$ ROI from the money they spare; whereas respondents with low self-control will get an ROI of $1.5 \%$. The level of customer satisfaction or surplus for each item exhibited in the laboratory setting is designed so that the expected value of the consumer surplus equals to the ROI. In general, the incentives from the satisfaction level of buying goods can be lower, equal to or higher than the incentives of the benefits of the spare money (ROI).

In the laboratory study, the number of experiments performed per day, on average, was 5 experiments. It took between 10-15 minutes per experiment, depending on the treatments. This strategy is effective because it has been previously socialized in three classes that are large enough to run 3 replications for each treatment. The number of enumerators on duty is 9 people, with the division of tasks as follows:

a. Two people acted as officers, explaining the purpose of the study and the treatment undertaken.

b. Five people acted as shopkeepers, and provided additional explanations to the respondents, and helped the respondents to fill out the decision sheets. 
c. One person acts as the officer who enters the data of the respondent's decision and counts the number of incentives provided by the respondent.

d. One person acts as a cash officer, who pays incentives to respondents. The steps undertaken are as follows:

a. The enumerator prepares the lab/class used to perform the experiment in accordance with the treatment.

b. Five respondents enter the lab and occupy the space provided for an explanation.

c. The officer provided an explanation on the purpose of the study and the type of treatment performed on the respondent. The explanation is accompanied by props (consumer surplus value and Return on Investment/ROI) brought by the officer.

d. After getting an explanation, the respondents were given a decision sheet and a specimen (money) with a total nominal value of IDR 200,000 (small or large denomination).

e. Respondents make purchases of goods in stores that have been displayed with the types of goods in accordance with the treatment.

f. After conducting the transaction, the respondent heads to the cashier.

g. The cashier records the type of goods purchased and calculates the amount of incentive received.

h. Respondents receive incentives from the officers and sign the attendance list to prove that they had conducted the experiments.

i. The experiment finishes and the respondent leaves the lab.

\subsection{Subject Incentives in the Laboratory Study}

In the laboratory study, in addition to incentive money for arrival (e.g. IDR $200,000 / X)$, the subject can get a bonus consisting of customer satisfaction of the goods he purchased (SK), and ROI of the remaining money that is not spent. The total incentives obtained by the subject are as follows:

IDR $200,000 / X+(S K+R O I)$

The correction factor $X$ in this experiment depends on the availability of the research funding, for example, using the correction factor $X=10$, so the total incentive given is IDR 20,000, - plus bonus, that represents the consumer surplus (SK) of the total expenditure and the ROI of the remaining money (not spent), based on the simulation results conducted by the subjects.

\subsection{Experimental Design of the Field Study}

The experimental design of the field study, used in assessing the factors that influence community spending, is the Factorial Complete Random Design (FCRD). Similar to the design of the laboratory study, there are four main factors studied that are namely the denomination (F1), prices of goods (F2), expenditure planning (F4), and market types (F5). The self-control is the characteristic of innate respondents, which may affect the pattern of shopping. It serve as covariate in field study, while 
serve as main factor (F3) in previous laboratory study. The characteristics of the respondent may include "residence", education, employment, income per capita, and level of need. The consumers who "reside in the city" are thought to have "low self-expenditure control", so their spending tends to be higher than those living in the district or village. Response variable from this research is respondent's purchase, using the allocated IDR 200,000 banknote. Data obtained from the field study activity was analyzed with ANCOVA. In addition to examining the four key factors that are applied, ANCOVA also examines other uncontrolled variables, which may affect the response variables (spending). This uncontrolled variable is called a covariate. In general, the ANCOVA model can be represented by:

$$
\begin{aligned}
& \mathrm{Y}_{\mathrm{ijklm}}=\mu+\alpha_{\mathrm{i}}+\beta_{\mathrm{j}}+\delta_{\mathrm{k}}+\mathrm{p}_{1}+(\alpha \beta)_{\mathrm{ij}}+(\alpha \delta)_{\mathrm{ik}}+(\alpha p)_{\mathrm{il}}+(\beta \delta)_{\mathrm{jk}}+(\beta \mathrm{p})_{\mathrm{jl}}+(\delta p)_{\mathrm{kl}}+(\alpha \beta \delta)_{\mathrm{ijk}}+ \\
& (\alpha \beta p)_{\mathrm{ijl}}+(\beta \delta p)_{\mathrm{jkl}}+(\alpha \beta \delta p)_{\mathrm{ijkl}}+\Phi\left(\mathrm{Keb}_{\mathrm{ijkl}}-\overline{\mathrm{Keb}}\right)+\zeta\left(\mathrm{Pdd}_{\mathrm{ijkl}}-\overline{\mathrm{Pdd}}\right) \\
& +\tau\left(\mathrm{Pkj}_{\mathrm{ijkl}}-\overline{\mathrm{Pkj}}\right)+v\left(\mathrm{Pdpt}_{\mathrm{ijkl}}-\overline{\mathrm{Pdpt}}\right)+\mathrm{Q}\left(\mathrm{TT}_{\mathrm{ijkl}}-\overline{\mathrm{TT}}\right)+\varepsilon_{\mathrm{ijklm} .}
\end{aligned}
$$

$\mathrm{Y}_{\mathrm{ij} \mathrm{jlm}} \quad$ : Total individual/community spending with the $\mathrm{k}$-th level expenditure planning for the $j$-th price of goods using the $i$-th denomination on the l-th market

$\mu, \alpha_{\mathrm{i},} \beta_{\mathrm{j},} \delta_{\mathrm{k}}$ : Similar with the previous model

$p_{1} \quad$ : Influence of the 1 -th market types, $(1=1$ minimarket; $1=2$ traditional market)

$(\alpha p)_{\text {il }} \quad:$ The influence of interaction between the i-th denomination and the 1-th market type

(The effect of denominations on spending depends on the type of market)

$(\beta p)_{j 1} \quad:$ The effect of interaction between the $j$-th value and 1-th market type (The effect of price on spending depends on the type of market)

$(\delta p)_{\mathrm{kl}} \quad:$ The effect of interaction between the $\mathrm{k}$-th level of expenditure planning and the 1-th market type (The influence of expenditure planning level on shopping depends on the market type)

$(\alpha \beta p)_{\mathrm{ij} 1} \quad:$ The effect of the interaction between the i-th denomination, the price of the $\mathrm{j}$-th goods and the l-th market type (The denominational effect on spending depends on both the price of the goods and the type of market)

$(\beta \delta p)_{j \mathrm{kl}} \quad$ : The effect of the interaction between the price of the $\mathrm{j}$-th goods, the level of the k-th expenditure planning and the l-th market type (The influence of the price of goods on spending depends on the level of expenditure planning and market type)

$(\alpha \beta \delta p)_{\mathrm{ijkl}} \quad$ : The influence of the interaction between the i-th denomination with the $\mathrm{j}$-th price of goods, the k-th expenditure planning, and the l-th market type (The denominational effect on spending depends on the price of goods, the level of expenditure planning, and the type of market) 
$\varepsilon_{\mathrm{ijkl}}$

: Error for individual/community spending with the level of $\mathrm{k}$-th expenditure planning for the $j$-th price of goods using the $i$-th denomination on the l-th market, in the m-th replicate

In addition to the main factors, this analysis also examines the innate characteristics of respondents as covariates that may affect the pattern of their spending. The influence of these characteristics consists of:

$\omega\left(\mathrm{Keb}_{\mathrm{ijkl}}-\overline{\mathrm{Keb}}\right) \quad$ : Similar with the previous model.

$\zeta\left(\operatorname{Pdd}_{\mathrm{ijk}}-\overline{\mathrm{Pdd}}\right)$ : The effect of education on individual/community with the i-th denomination expenditures the $\mathrm{j}$-th price goods, the level of $\mathrm{k}$-th expenditure planning, and the 1-th type of market, corrected with the average level of education of all respondents.

$\tau\left(\mathrm{Pkj}_{\mathrm{j} \mathrm{jk}}-\overline{\mathrm{Pkj}}\right) \quad$ : The effect of employment on individual/community shopping with the i-th denomination, the j-th price of goods, the level k-th expenditure planning, and the type of the l-th market.

$v\left(\mathrm{Pdpt}_{\mathrm{ijk1}}-\overline{\mathrm{Pdpt}}\right)$ :The effect of per capita income on individual/community spending with the $i$-th denomination, the $j$-th price of goods, the level of the k-th expenditure planning, and the type of the l-th market, corrected with the average per capita income rate.

$\mathrm{Q}\left(\mathrm{TT}_{\mathrm{ijk}}-\overline{\mathrm{TT}}\right) \quad$ : The effect of the place of residence on the spending of individuals/ community with the i-th denomination, the j-th price of goods, the level of the k-th expenditure planning, and the type of the 1-th market. The residence here is used as a proxy for self-control.

\subsection{Sampling Method in the Field Study}

The sample of field study involve 120 respondents from two locations, Bogor district and Bogor city. The sampling method on selecting respondent uses purposive sampling with quota. The predetermined quota is 60 respondents for the city and 60 respondents for the district. All respondents selected are subject to predetermined selection criteria.

As described in the previous laboratory study, the present study aims to examine the influence of denominations and the other three factors (price, planning, and place of shopping) on shopping. In the application of denominational and price factors, respondents were randomly selected by the researchers. The approach used for the denominational factor (F1) is to give two pieces of IDR 100,000 denominated together with a paperclip for large denominations; and one IDR 50,000, three IDR 20,000, six IDR 10,000 and six IDR 5,000 for a small denomination, similar to the Laboratory Study design. As for the level of price factor of goods (F2), high prices include goods with prices above IDR 100,000 while low prices were goods with a maximum price of IDR 50,000.

This present study was conducted in two shopping places (factor of market type or F5) i.e. minimarket (Alfamart and Alfamidi) and traditional market which are located in the Regency and City of Bogor. The division of regions into districts and cities is done because "residence" is expected to represent the respondent's self-control which is one of the factors studied in this study. Nevertheless, in the implementation was found respondents who come from districts shop in the city 
or vice versa. This happens because the selected respondent is a community that is located in the research location. To address this, the location of the respondents' residence was analyzed as a covariate affecting the pattern of community spending.

Another studied factor is the presence or absence of shopping planning by the respondents. The approach taken for this F4 factor is the selection of people who already intend or will shop as respondents who have a plan, and the people who are around the research area but do not intend or not are spending as respondents who have no plan.

The respondents, in this study, are expected to represent every layer of the society in terms of economy. Therefore, the selected respondents are expected to represent the lower, middle, and upper classes of people who are represented based on the respondents' incomes. In addition, the selection of respondents also paid attention to the background of the respondent's work, which is expected to represent the works such as civil servants, self-employed, private, labor, student, job seeker, housewife, and retired. The selected respondents will be given an explanation of the treatment applied. The distribution of more complete respondents can be seen in Juanda (2015).

\section{RESULTS AND ANALYSIS}

\subsection{Laboratory Study Analysis Results}

The results of the analysis revealed that the price of goods (F2) and self-control (F3) significantly affect the individual decision to spend. Meanwhile, the denominational factor affect the spending decision when interacting with the price of goods and planning $(\mathrm{F} 1 \mathrm{xF} 2 \mathrm{xF} 4)$. In other words, the influence of denominations depends on the prices of goods and planning factors. Table 1 provide the ANCOVA model form Laboratory Study.

By only considering the denomination regardless of the good prices (F2), self control (F3), and spending plan (F4), there is no statistically significant difference in terms of total spending between small denomination consumers (Rupiah) and large denominations (or IDR 200,000). In individual interviews too, almost all of the (over 90\%) consumers thought that there was no difference in spending patterns when using large or small denominations. The average consumer spending with large denominations was IDR 119,043, which tended to be slightly smaller (but not significant) compared to consumers with small denominations (IDR 117,208). Some consumers felt that IDR 200,000 was more convenient or more practical to spend on various goods needs.

Overall there is a statistically significant difference between total consumer spending on low priced goods (maximum IDR 50,000 / unit) with total consumer spending on high priced items (above IDR 100,000 / unit) (regardless of the other three factors). From Figure 1, the average consumer spending on low-priced goods is IDR 94,375, smaller than consumer spending on high priced goods (IDR $141,875)$. For high-priced goods, tend to be high in the total shopping, since the variety of goods available in these two price categories (in this laboratory study) is relatively similar.

Overall, there is a (statistical) significant difference between the total consumer spending on low priced goods (maximum IDR 50,000/unit) and the total consumer 
spending on high priced goods (above IDR 100,000/unit) (regardless of the other three factors). In Figure 1, the average consumer spending on low-priced goods was IDR 94,375 which was smaller than that of the high-priced goods (IDR $141,875)$. For high-priced goods, the trend of high total shopping was large, since the variety of goods available in these two price categories (in this laboratory study) was relatively similar.

Regardless of the other 3 factors, there is (overall) a statistically significant difference between the total low self-control consumer spending and the total high self-control consumer spending. Seen from Figure 2, the average consumer spending with low self-control was IDR 124,375 which was bigger than the high self-control consumer spending (IDR 111,875). Consumers, who highly control themselves, will be more efficient in spending because they take into account the benefits of the remaining money for various purposes the benefits of which can be higher than that of the money spent immediately.

Table 1.

ANCOVA of the Laboratory Study

\begin{tabular}{lrrrrr}
\hline \multicolumn{1}{c}{ Source } & Sum of Squares & df & Mean Square & \multicolumn{1}{c}{ F } & Sig. \\
\hline Corrected Model & $51772496908.303^{\mathrm{a}}$ & 16 & 3235781056.769 & 13.132 & .000 \\
Intercept & 19993810831.864 & 1 & 19993810831.864 & 81.139 & .000 \\
Level of Needs & 34859431.359 & 1 & 34859431.359 & .141 & .708 \\
F1: Denomination & 53336458.016 & 1 & 53336458.016 & .216 & .643 \\
F2: Prices & 44958401356.233 & 1 & 44958401356.233 & 182.451 & .000 \\
F3: Self-Control & 2736573448.883 & 1 & 2736573448.883 & 11.106 & .001 \\
F4: Planning & 83356716.025 & 1 & 83356716.025 & .338 & .563 \\
F1*F2 & 125217672.191 & 1 & 125217672.191 & .508 & .479 \\
F1 *F3 & 68140813.314 & 1 & 68140813.314 & .277 & .601 \\
F1 *F4 & 18272330.624 & 1 & 18272330.624 & .074 & .786 \\
F2*F3 & 473232131.527 & 1 & 473232131.527 & 1.920 & .171 \\
F2*F4 & 99119432.153 & 1 & 99119432.153 & .402 & .528 \\
F3*F4 & 322820421.093 & 1 & 322820421.093 & 1.310 & .257 \\
F1*F2*F3 & 34260083.740 & 1 & 34260083.740 & .139 & .710 \\
F1*F2*F4 & 1374922112.766 & 1 & 1374922112.766 & 5.580 & .021 \\
& & & & & \\
F1*F3*F4 & 622494093.435 & 1 & 622494093.435 & 2.526 & .117 \\
F2*F3*F4 & 27961366.849 & 1 & 27961366.849 & .113 & .737 \\
F1*F2*F3*F4 & 1754066.087 & 1 & 1754066.087 & .007 & .933 \\
Error & 15524028893.086 & 63 & 246413157.033 & & \\
Total & 1183577763988.890 & 80 & & & \\
Corrected Total & 67296525801.389 & 79 & & & \\
\hline
\end{tabular}

a. R Squared $=.769$ (Adjusted R Squared $=.711$ )

Where F1 is the influence of denomination, F2 the price influence, F3 the influence of self-control and F4 the influence of shopping planning

Source: Juanda (2015) 


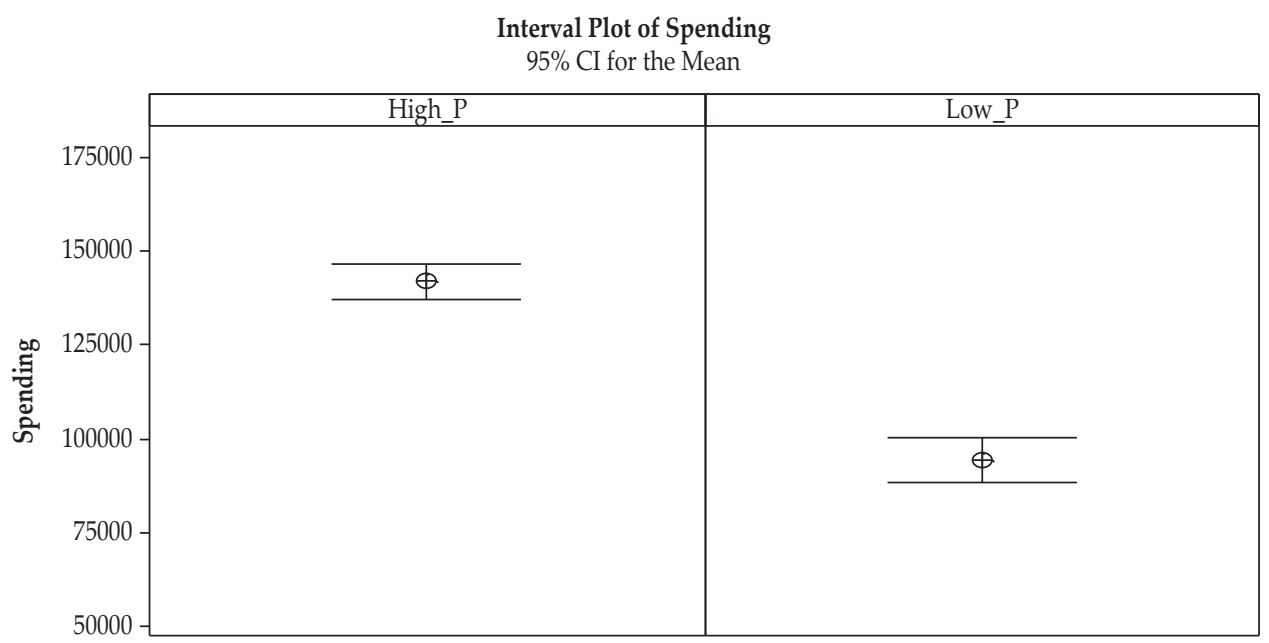

Panel variable: F2

Source: Juanda (2015)

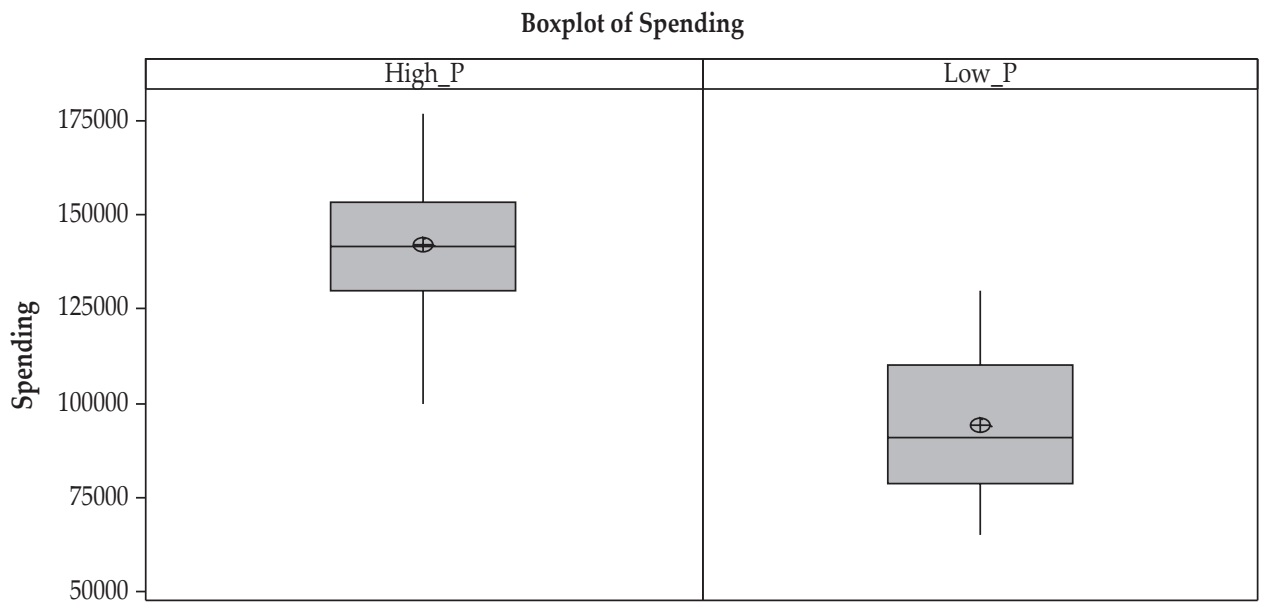

Panel variable: F2

Source: Juanda (2015)

Figure 1. Confidence level and Shopping Boxplot of 24 Consumer Groups for Low Price and 24 Consumer Groups for High Price 


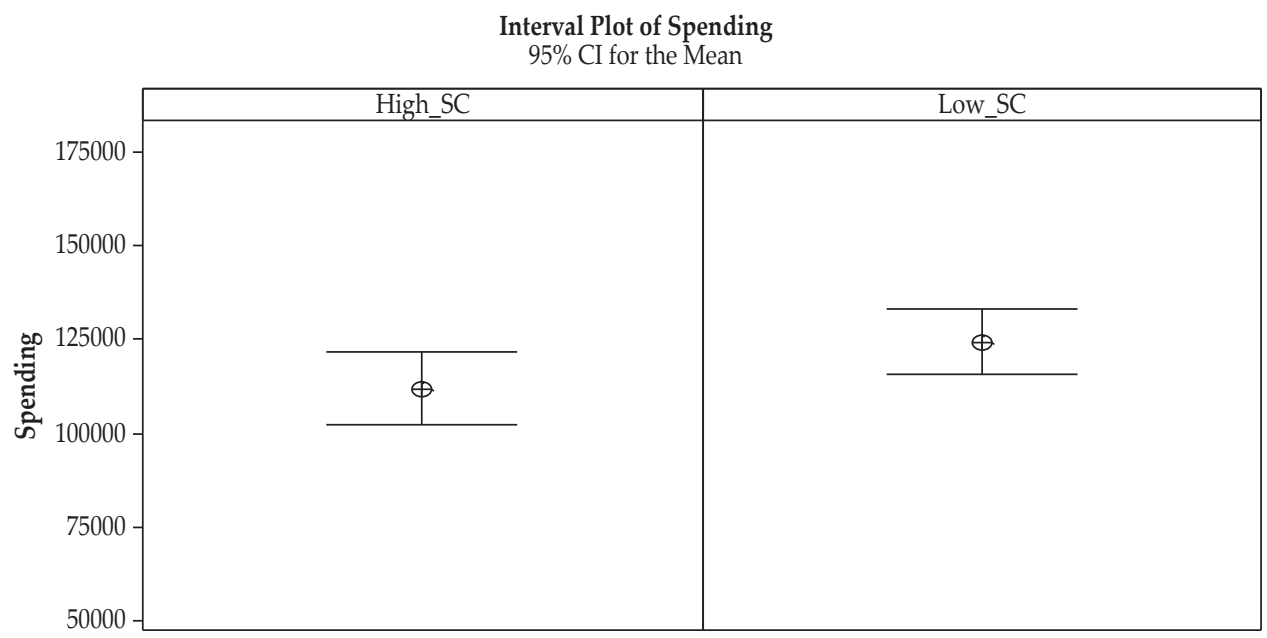

Panel variable: F3

Source: Juanda (2015)

Boxplot of Spending

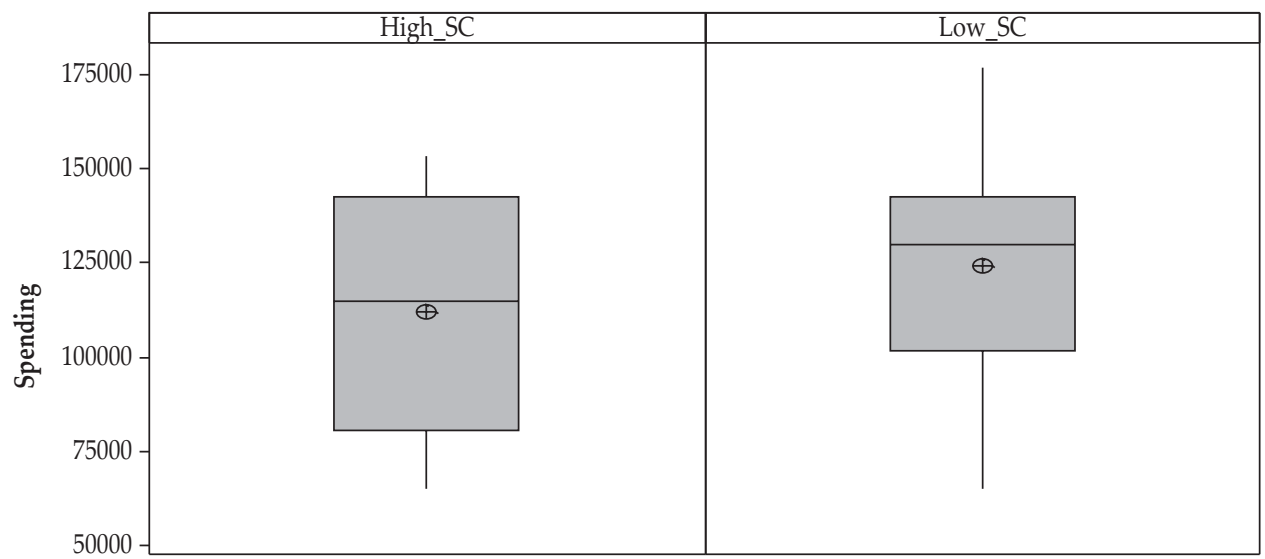

Panel variable: F3

Source: Juanda (2015)

Figure 2. Confidence level and Shopping Boxplot of 24 Consumer Groups for Low Self-Control and 24 Consumer Groups for High Self Control

The planning factor (regardless of the other three factors) was not significant in influencing the total expenditure (Table 1), although Figure 3a shows the average of consumer spending with pre-planned spending of IDR 119,166 which tends to be slightly larger than that of consumers without prior planning (IDR 117,083). Some consumers, who do have a shopping plan, tend to spend more because they already have the intention to spend before; although, it is not significant in this laboratory study, which may be due to the time difference in planning with relatively short shopping times (minutes). In a recent study by Juanda et al. (2016), 
where the planning was done at least one day before the respondent conducted an experimental simulation so that the consumer can do the planning carefully, has been proven that consumers who have planned the shopping are relatively higher as they take into account the long-term needs as well (see Figure 3b).

(a)

Interval Plot of Spending

95\% CI for the Mean

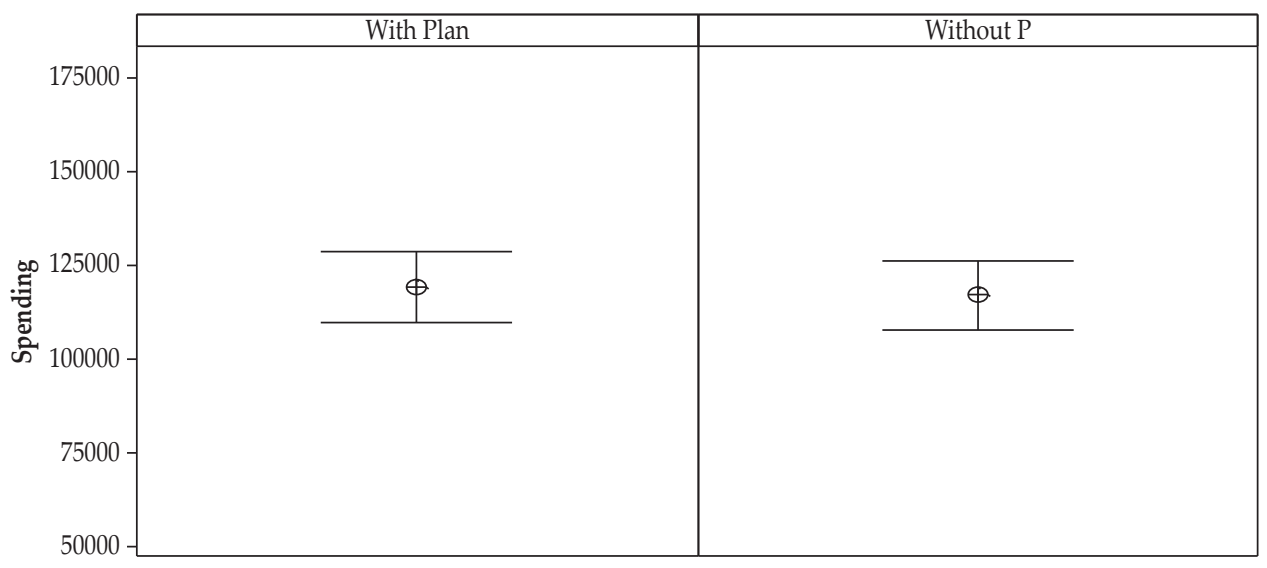

Panel variable: $\mathrm{F} 4$

Source: Juanda (2015)

(b)

Interval Plot of Spending

95\% CI for the Mean

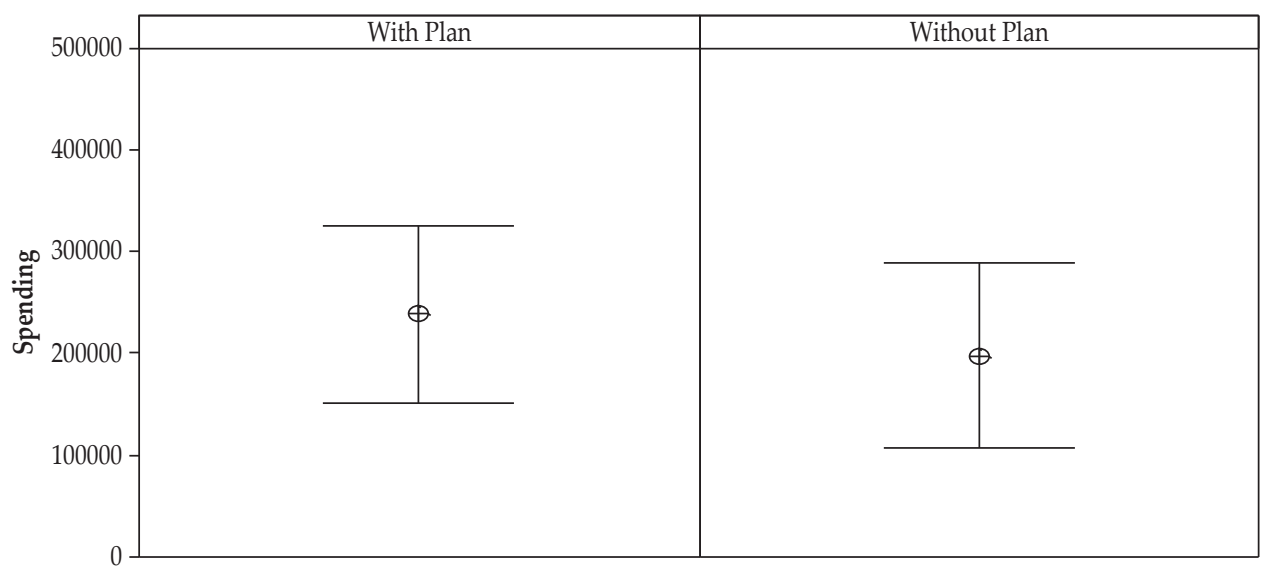

Panel variable: Planning

Source: Juanda et al. (2016)

Figure 3. Confidence level of Consumer Group Shopping Without Planning and Consumer Groups Without Planning 
Based on Figure 4a, there is a tendency of denominational influence depending on the price of goods. For high-priced goods, the respondents with large denomination have a tendency to spend more (IDR 144,000) than respondents holding small denominations (IDR 139,750). This is because respondents feel that the large denominations are more practical for high priced goods. Conversely, for low prices, respondents with small denominations have more spending tendencies (IDR 94,667) than large denominations (IDR 94,083). Respondents argued it is more efficient to use small denominations to purchase low price goods.

In Figure $4 b$, it can be clearly seen that (in the analysis) the denominational influence tends to depend on the price of goods. When the price of goods are hight, the effect of large denomination on spending is larger than the small denomination. From the results of this analysis, it can be implied that regions with relatively high-priced goods such as eastern Indonesia, need to be provided with (more) larger denominations.

As mentioned in the ANCOVA results in Table 1, the influence of the denomination depends on the price of the goods and the planning of the shopping. For the group of respondent without spending plan, the average spending on high-priced goods when using large denominations is relatively larger than when using small denominations.

Consumers feel that fractions of IDR 200,000 are easier or more practical for shopping various needs of goods. While respondents with planning, average spending on goods with high prices, is relatively the same using small denominations, as well as the large denominations (Figure 5a).

In Figure $5 b$, it can be seen that respondents without planning, average spending on goods with low prices are relatively larger when using small denominations compared to large denominations. Consumers are reluctant to spend large denominations on low-priced goods. As for the planning, the average spending on goods with low prices is relatively larger when using large denominations compared to small denominations as the consumers feel that fractions of IDR 200,000 are easier or more practical for shopping various needs of goods that have been planned to be purchased. 
(a)

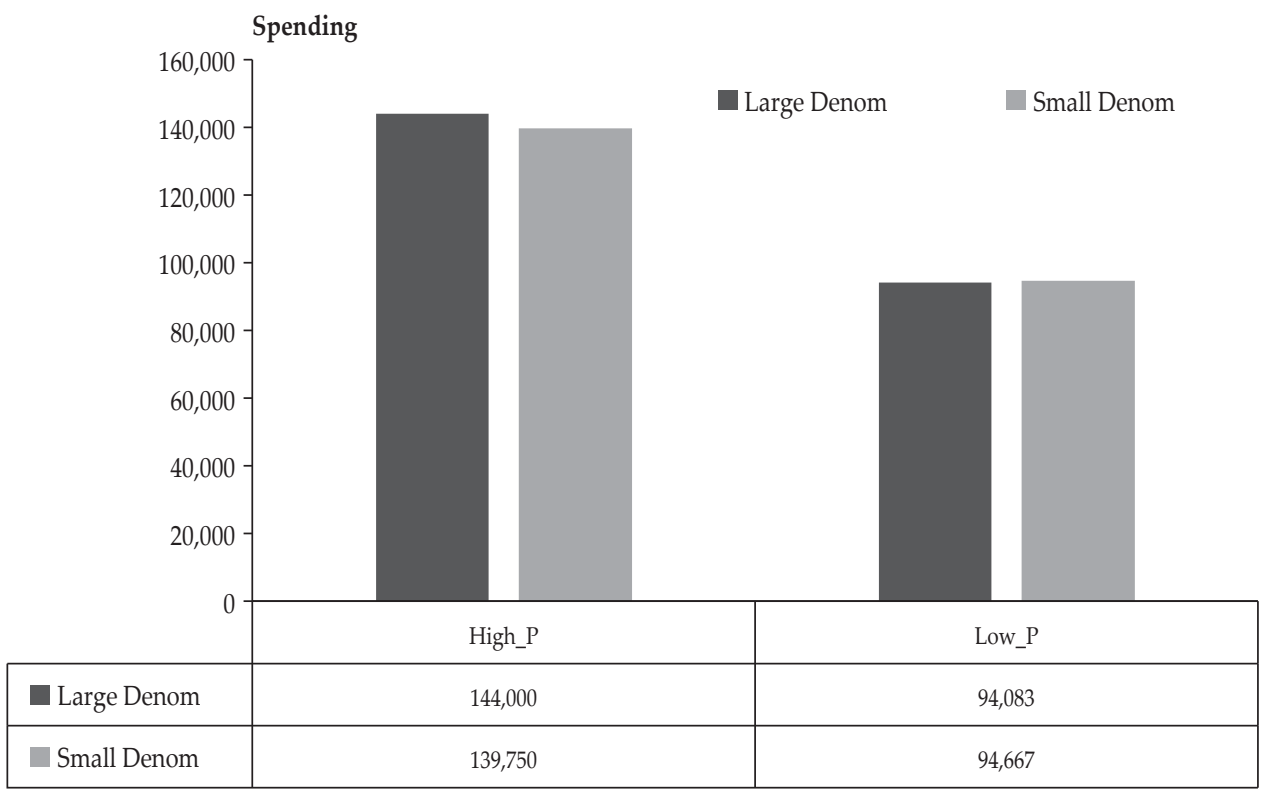

Source: Juanda (2015)

(b)

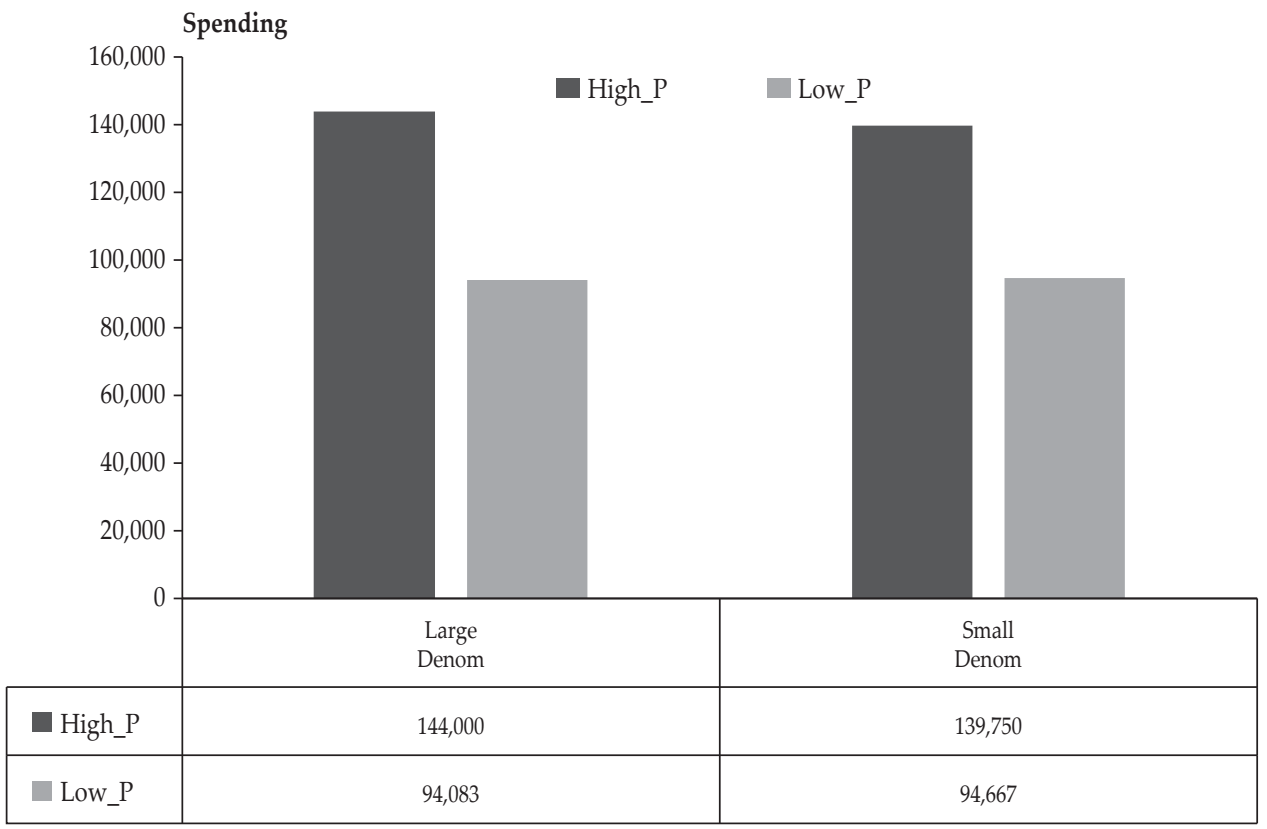

Source: Juanda (2015)

Figure 4. Average Shopping When Using Large Denominations and Small Denominations at Each Price Level (Low Price and High Price) 
(a)

\section{High Price}

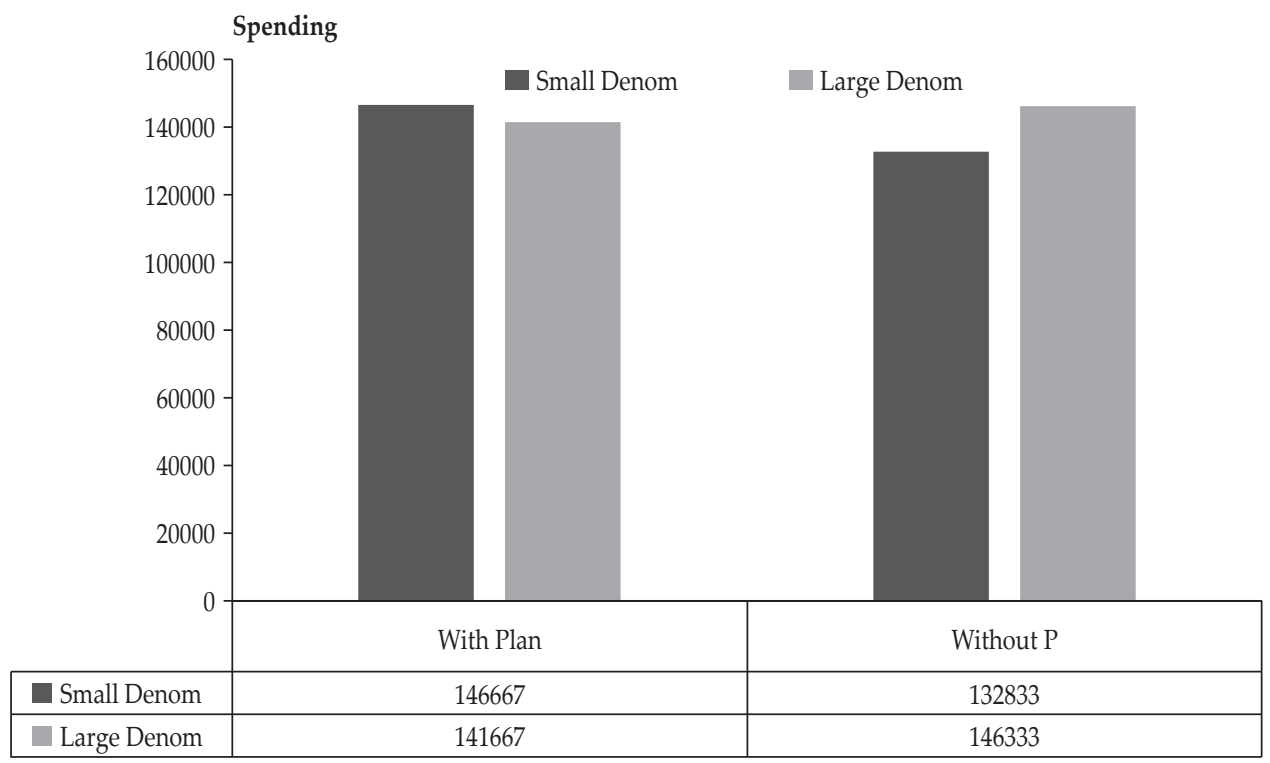

Source: Juanda (2015)

(b)

\section{Low Price}

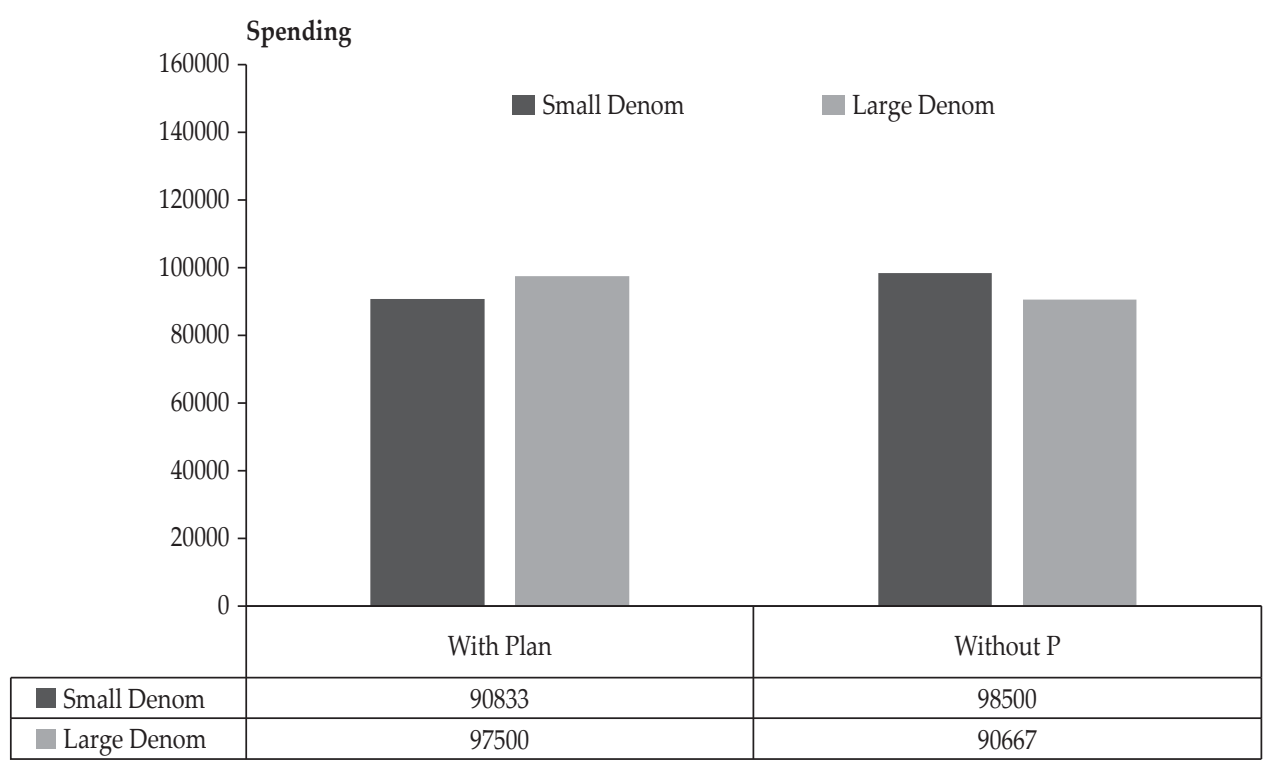

Source: Juanda (2015)

Figure 5. Average Expenditure When Using Large Denominations and Small Denominations for Respondents Who Have Planned and Not Planned Based on Group of Goods at Different Prices (Low and High) 
In Figure 6, it is also clear that the effect of large denominations on the difference in spending between high-value and low-value goods is greater than that of small denominations (if not planned). From this analysis, it can also be implied that areas with relatively high prices of goods such as eastern Indonesia, need to be provided with larger denominations as the relatively high price of goods requires larger denominations.

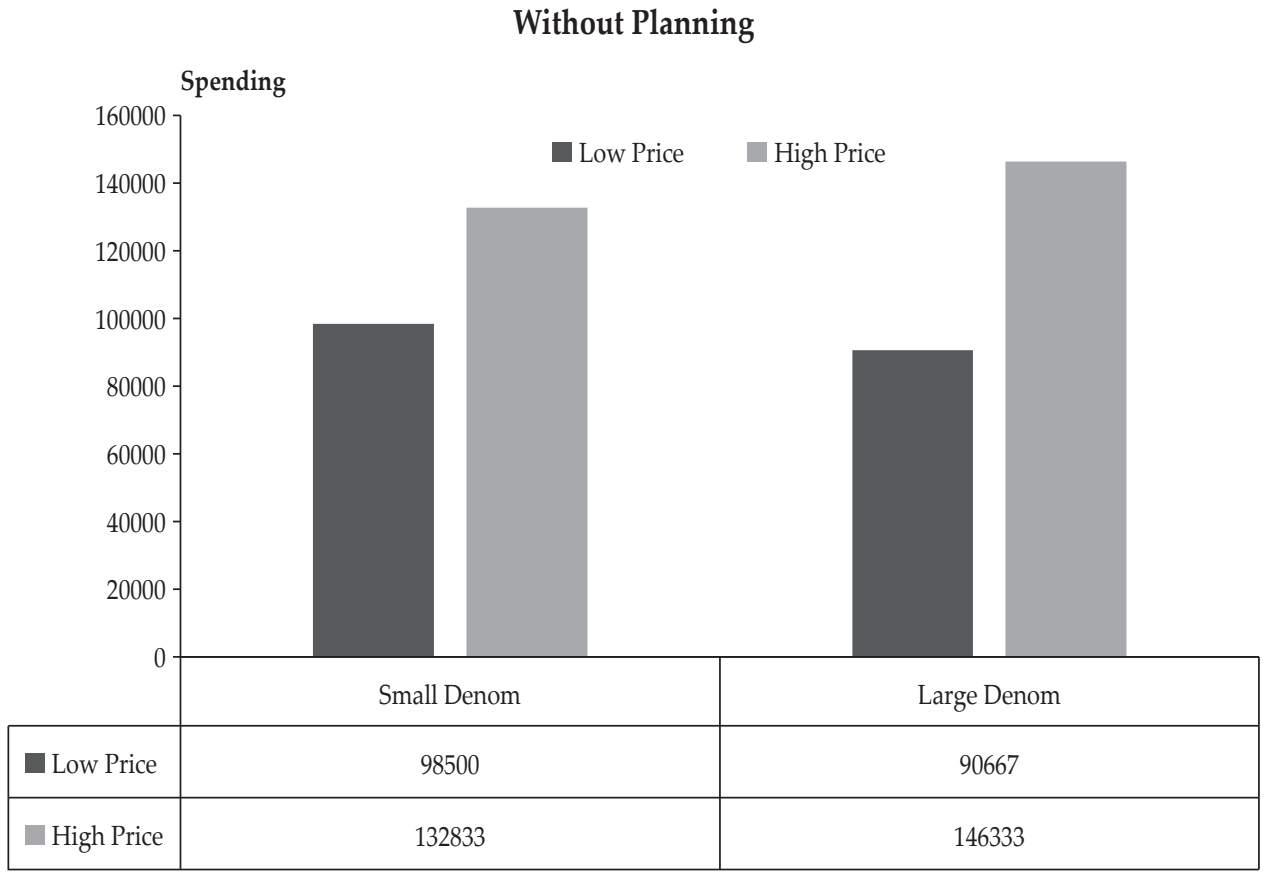

Source: Juanda (2015)

Figure 6. Average Shopping Using Large Denominations and Small Denominations for Each Price (Low Price and High Price) without Planning

\subsection{Field Study Analysis Results}

The field study location was divided into two areas i.e. city and district. In each region, surveys were conducted on Alfamart and Alfamidi minimarkets and traditional markets. In the city area, the selected minimarket was Alfamart Citra Gandaria located on Jl. Achmad Adnawi Jaya, North Bogor and Alfamidi Bangbarung on Jl. Bangbarung Raya kav. 13-15 RT. 05/014 Kelurahan Tegal Gundil, North Bogor. While the selected traditional market was Pasar Induk Warung Jambu which is located in Jl. Pajajaran and Pasar Anyar on Jl. Dewi Sartika in the City of Bogor. Research in the district area was conducted at Alfamart Cihideung Ilir which is situated on Jl. Raya Cibanteng, KM. 10 Cihideung Ilir Ciampea, and Alfamidi Babakan Raya located on Jl. Babakan Raya. As for the traditional market, Pasar Dramaga which is located at Jl. Dramaga Desa Dramaga Kec. Dramaga Kab. Bogor was selected. 
The result of ANCOVA model analysis can be seen in Table 2. The result shows the price (F2), planning (F4), and the market type (F5), significantly affect the individual spending decision. While the influence of denominations (F1) on expenditure depended on the type of market for shopping (F5) and the price of goods (F2), in the form of the interaction effect between 2 Factors F1xF5, and interaction influence between 3 Factors F1xF2xF5. On the other hand, the effect of planning (F4) on spending depended on the type of market where the shopping (F5) was carried out which was an interaction between 2 Factors F4xF5.

In Table 2, it can also be observed that respondent's residence (District of City) influenced shopping. The average of total expenditure of Respondents live in the city (IDR 128,361) was greater than that of respondents living in the district (IDR $118,603)$. The likelihood of urban respondent needs is higher, more extravagant, or self-control for shopping is low.

Without taking into account the other 3 factors, overall, there is no statistical significant difference in terms of the total spending between small denomination (Rupiah) consumers and those using large denominations such as IDR 200,000. In individual interviews as well, almost all ( $88 \%$ ) of the consumers believed that there is no difference in spending patterns when using large and small denominations. Respondents with different shopping patterns argued that if they hold large denominations they are reluctant to shop and prefer to keep the money if the price of goods is low. In Figure 7, the average consumer spending with large denominations was IDR 123,110, which was slightly smaller (but not significant) compared to consumers with small denominations (IDR 118,916). Some consumers felt that the IDR 200,000 was easier or more practical for shopping various needed goods. The results of the analysis for this field of study were consistent with the results of the analysis for the laboratory study.

Table 2.

ANCOVA for the Field Study

\begin{tabular}{lrrrrr}
\hline \multicolumn{1}{c}{ Source } & \multicolumn{1}{c}{ Sum of Squares } & df & Mean Square & \multicolumn{1}{c}{ F } & Sig. \\
\hline Corrected Model & $54351986733.398^{\mathrm{a}}$ & 20 & 2717599336.670 & 2.298 & .004 \\
Intercept & 30387826330.395 & 1 & 30387826330.395 & 25.692 & .000 \\
LEVEL OF NEEDS & 1932892886.761 & 1 & 1932892886.761 & 1.634 & .204 \\
JOB & 322500723.171 & 1 & 322500723.171 & .273 & .603 \\
INCOMES_KPT & 72334659.020 & 1 & 72334659.020 & .061 & .805 \\
EDUCATION & 973457278.947 & 1 & 973457278.947 & .823 & .366 \\
RESIDENCE & 4291188291.658 & 1 & 4291188291.658 & 3.628 & .060 \\
F1: Denomination & 448195216.237 & 1 & 448195216.237 & .379 & .540 \\
F2: Price & 6036967887.085 & 1 & 6036967887.085 & 5.104 & .026 \\
F4: Planning & 8387348438.352 & 1 & 8387348438.352 & 7.091 & .009 \\
F5: Shopping Center & 3513766386.817 & 1 & 3513766386.817 & 2.971 & .088 \\
F1 *F2 & 68738611.971 & 1 & 68738611.971 & .058 & .810 \\
\hline
\end{tabular}


Table 2.

ANCOVA for the Field Study (Continued)

\begin{tabular}{|c|c|c|c|c|c|}
\hline Source & Sum of Squares & df & Mean Square & F & Sig. \\
\hline $\mathrm{F} 1{ }^{*} \mathrm{~F} 4$ & 20659354.006 & 1 & 20659354.006 & .017 & .895 \\
\hline $\mathrm{F} 1{ }^{*} \mathrm{~F} 5$ & 4342356549.413 & 1 & 4342356549.413 & 3.671 & .058 \\
\hline $\mathrm{F} 2 * \mathrm{~F} 4$ & 885977184.493 & 1 & 885977184.493 & .749 & .389 \\
\hline $\mathrm{F} 2 * \mathrm{~F} 5$ & 575986618.332 & 1 & 575986618.332 & .487 & .487 \\
\hline $\mathrm{F} 4 * \mathrm{~F} 5$ & 9669085619.282 & 1 & 9669085619.282 & 8.175 & .005 \\
\hline $\mathrm{F} 1{ }^{*} \mathrm{~F} 2 * \mathrm{~F} 4$ & 2271805492.760 & 1 & 2271805492.760 & 1.921 & .169 \\
\hline $\mathrm{F} 1{ }^{*} \mathrm{~F} 2 * \mathrm{~F} 5$ & 8853106192.773 & 1 & 8853106192.773 & 7.485 & .007 \\
\hline $\mathrm{F} 1{ }^{*} \mathrm{~F} 4{ }^{*} \mathrm{~F} 5$ & 248878275.060 & 1 & 248878275.060 & .210 & .647 \\
\hline $\mathrm{F} 2 * \mathrm{~F} 4 * \mathrm{~F} 5$ & 18673071.133 & 1 & 18673071.133 & .016 & .900 \\
\hline $\mathrm{F} 1{ }^{*} \mathrm{~F} 2 * \mathrm{~F} 4 * \mathrm{~F} 5$ & 14061424.874 & 1 & 14061424.874 & .012 & .913 \\
\hline Error & 117095112402.193 & 99 & 1182778913.153 & & \\
\hline Total & 1989154820109.000 & 120 & & & \\
\hline Corrected Total & 171447099135.592 & 119 & & & \\
\hline
\end{tabular}

a. $\mathrm{R}$ Squared $=.317$ (Adjusted R Squared $=.179$ )

Where F1 is the influence of denomination, F2 price influence, the F4 influence of shopping planning and F5 the type of shopping place.

Source: Juanda (2015)

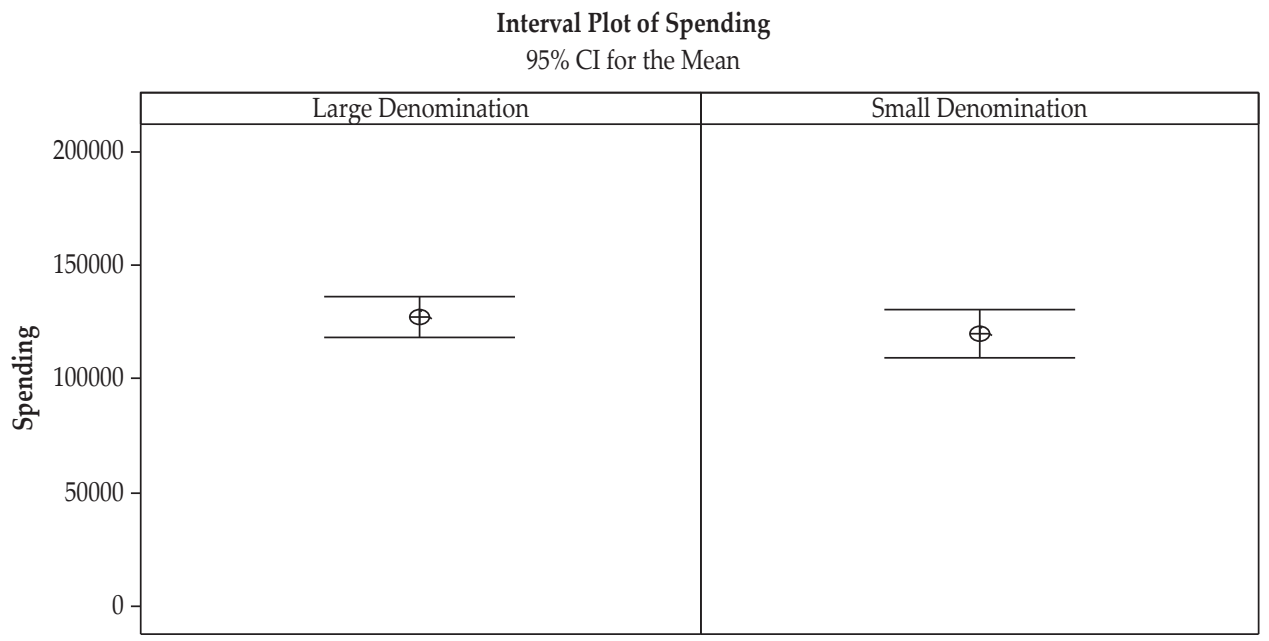

Panel variable: Denomination

Source: Juanda (2015) 


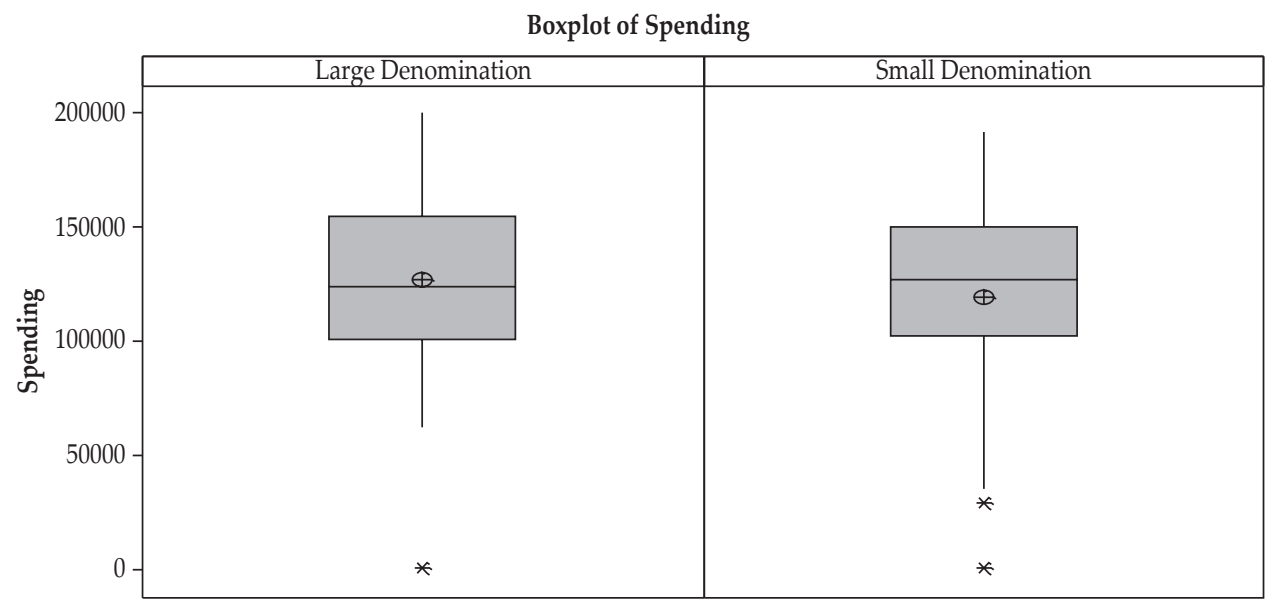

Panel variable: Denomination

Source: Juanda (2015)

Figure 7. Confidence level and Boxplot of Shopping for 60 Consumers Using Small Denominations and 60 Consumers Using Large Denominations

The price factor has a significant effect on consumer spending (if no regard for the other three factors). Overall, the total consumer spending on low priced goods (maximum IDR 50,000/unit) differed from the total consumer spending on high priced goods (above IDR 100,000/unit). In Figure 8, the average consumer spending for low priced goods was IDR 113,114 which was smaller than the average consumer spending on high priced goods (IDR 128,882). The goods with high prices tended to have a higher total shopping. As for low-priced goods, most consumers wanted to keep some of their money for "other purposes" or will spend when it is really needed. The results of this analysis are also consistent with the results of the analysis for the laboratory study.

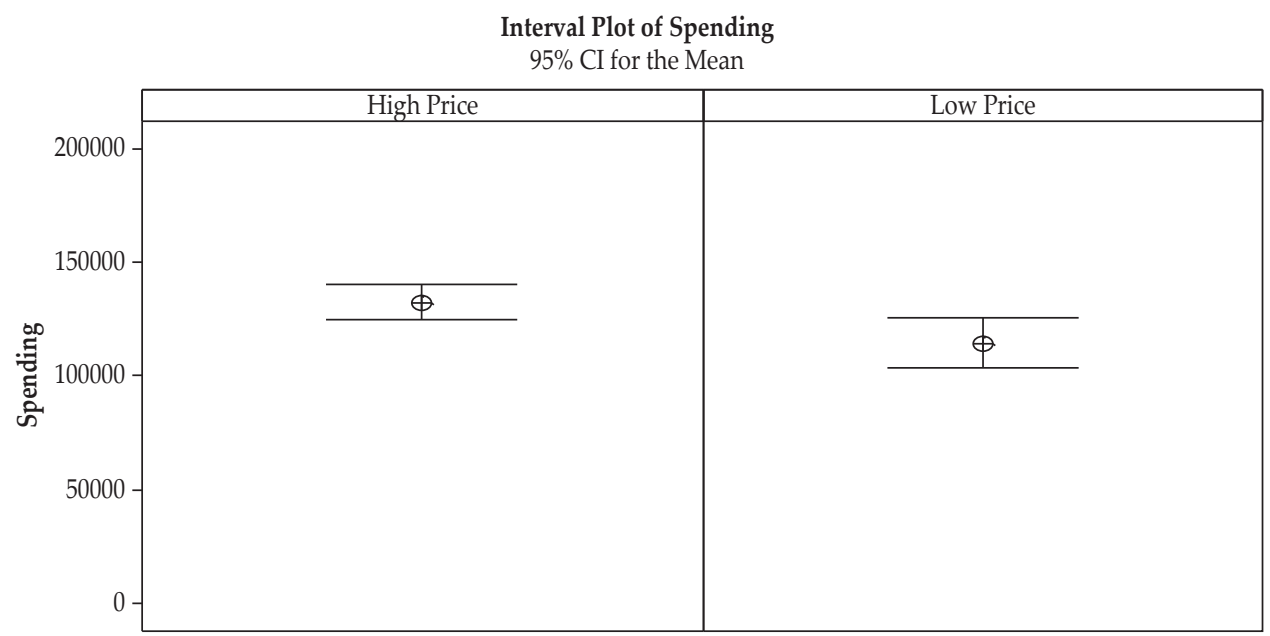




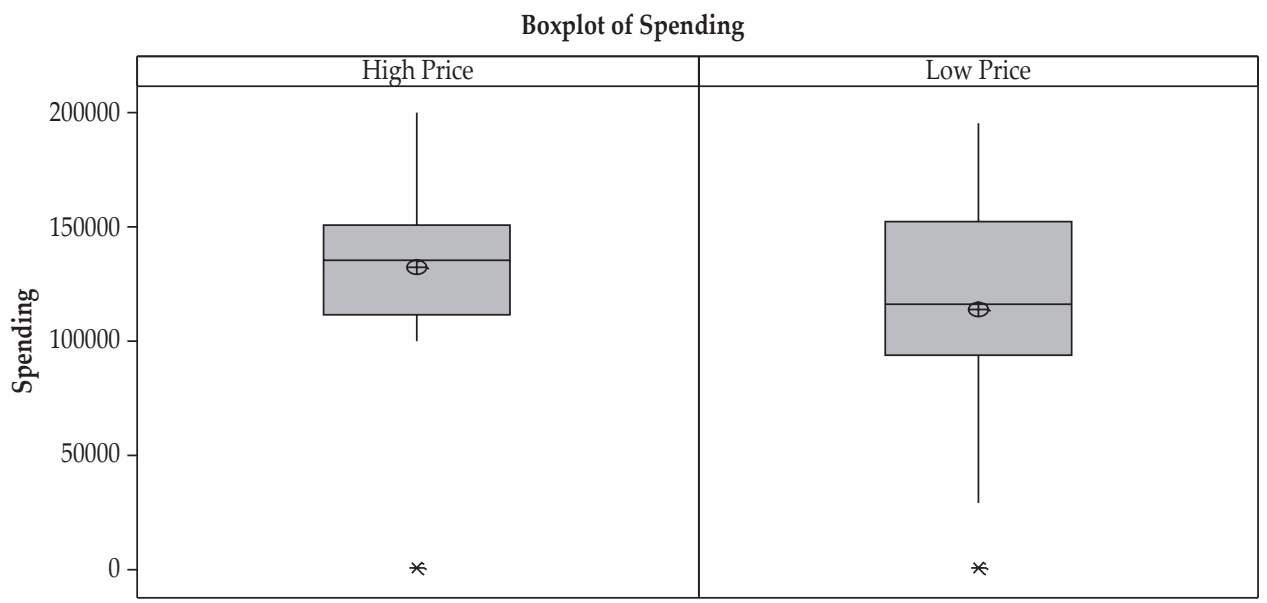

Panel variable: Price

Source: Juanda (2015)

Figure 8. Confidence Levels and Boxplot Shopping for 60 Consumers for Low Price and 60 Consumers for High Price

Regardless of the other 3 factors, there is, overall, a statistically significant difference between the total spending of consumers that made planning prior to shopping and those who had not planned the shopping. In Figure 9, the average consumer spending, for those who have not yet made a plan, is IDR 111,962 which is smaller than the consumer spending with prior planning (IDR 130,064). The consumers, who already have a plan, already know what items to buy and respondents can also buy items that have not been planned. This trend is consistent with laboratory study results.

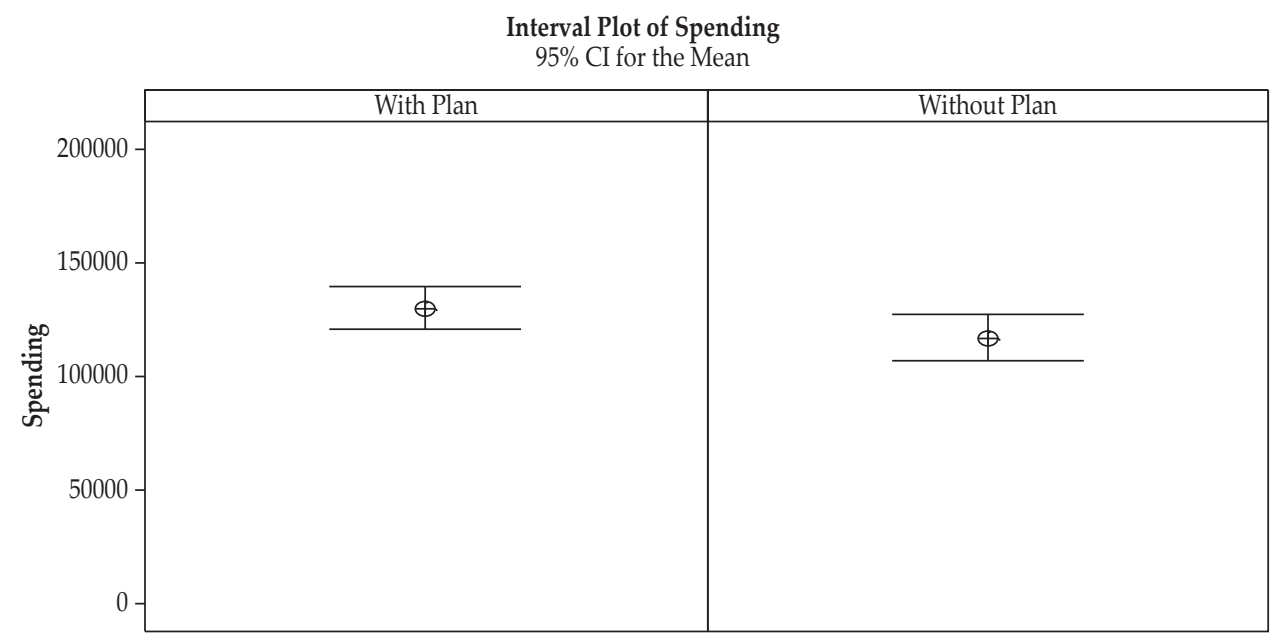

Panel variable: Planning

Source: Juanda (2015) 


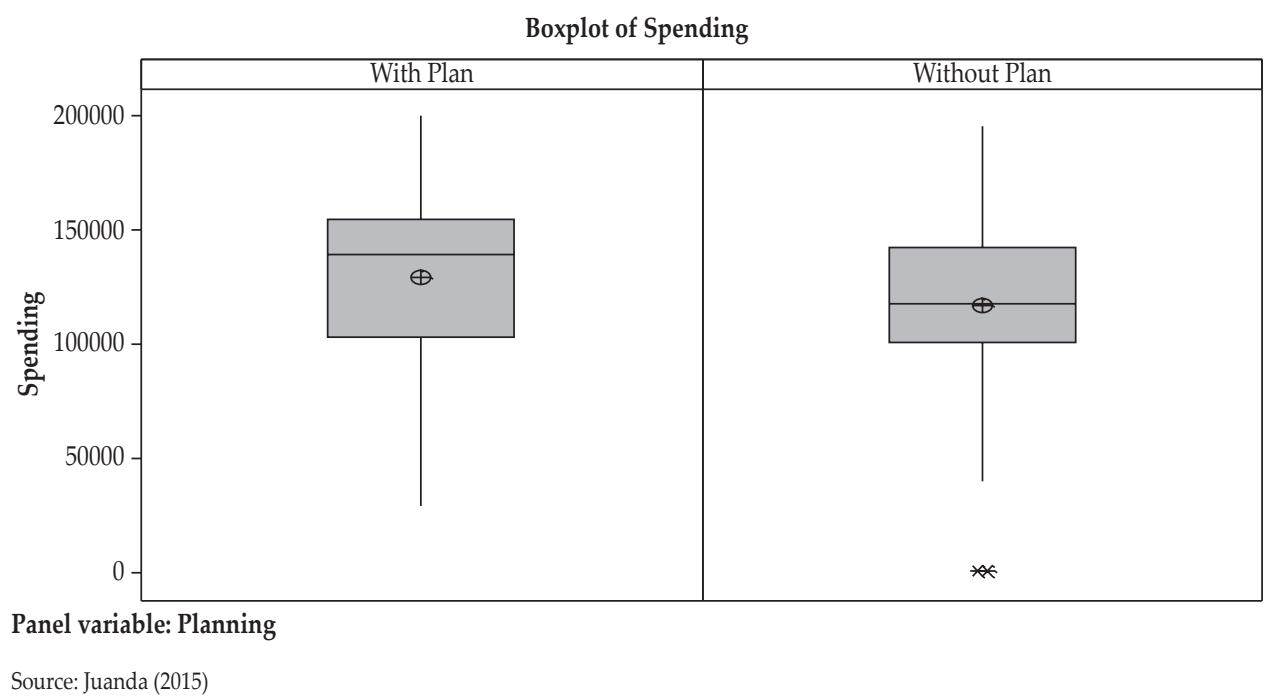

Figure 9. Boxplot and Confidence Level of Shopping for 60 Consumers with Planning and 60 Consumers without Planning

Overall, there is a statistically significant difference in terms of total shopping expenditures of consumers in the minimarket and consumers who shop in traditional markets, without paying attention to all of the three other factors. Based on Figure 10, the average consumer shopping expenditure, in the traditional market, was IDR 114,896 which was smaller than the average consumer spending in minimarket (IDR 127,165). This difference is due to the variety of goods in the mini market that are in a single location, making it easier for consumers to shop, in contrast to traditional markets where the shopping locations are spread out on market areas.

In addition to the four main factors studied, the total consumer spending was also influenced by the inherent characteristics of the respondents which, in this analysis, became covariates. These characteristics included the level of needs, education, occupation, expenditure, per capita income, and respondent's residence. Based on the results of ANCOVA as presented in Table 2, the covariates that have significant effect on consumer spending decisions was the respondents' residence, where respondents who live in the city spend higher on average (IDR 128,361 ) compared to those living in the district (IDR 118,603), as seen in the Figure 11. This is a consequence of the fact that the level of needs of the people living in cities is larger than those living in the districts. There is a (though insignificant) tendency that the total spending tends to be higher for people with higher per capita incomes, larger monthly expenditures, and higher levels of education of the respondents. 


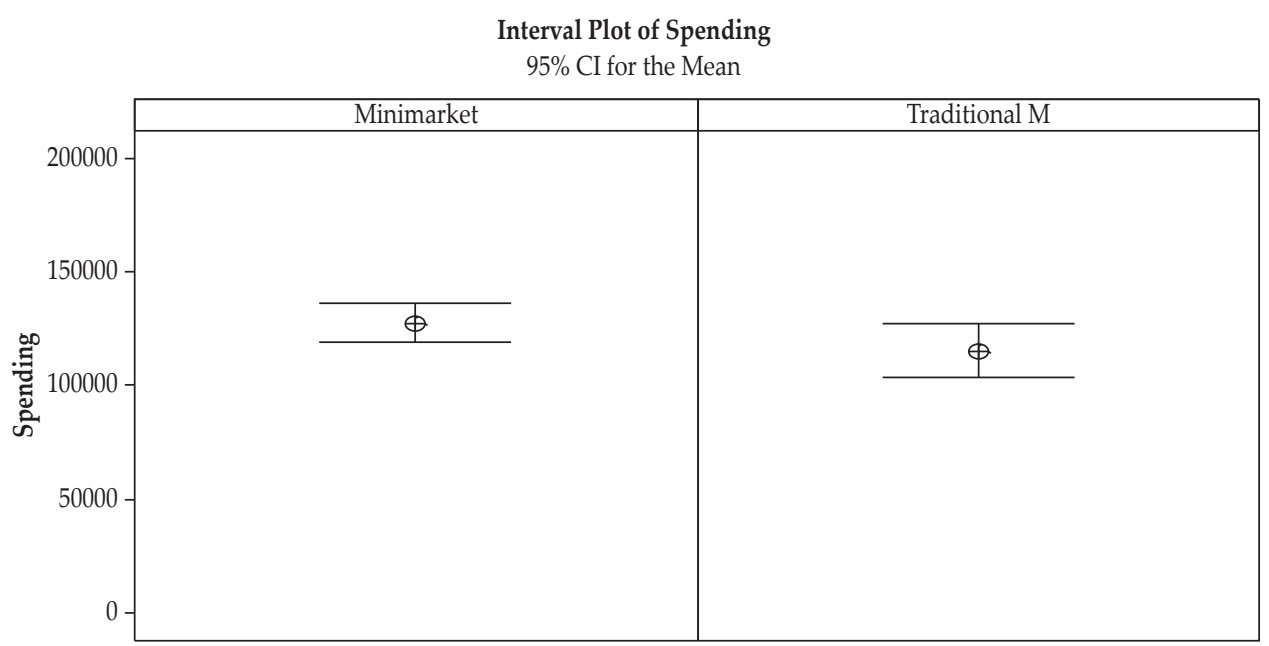

Panel variable: Shopping Center

Source: Juanda (2015)

Boxplot of Spending

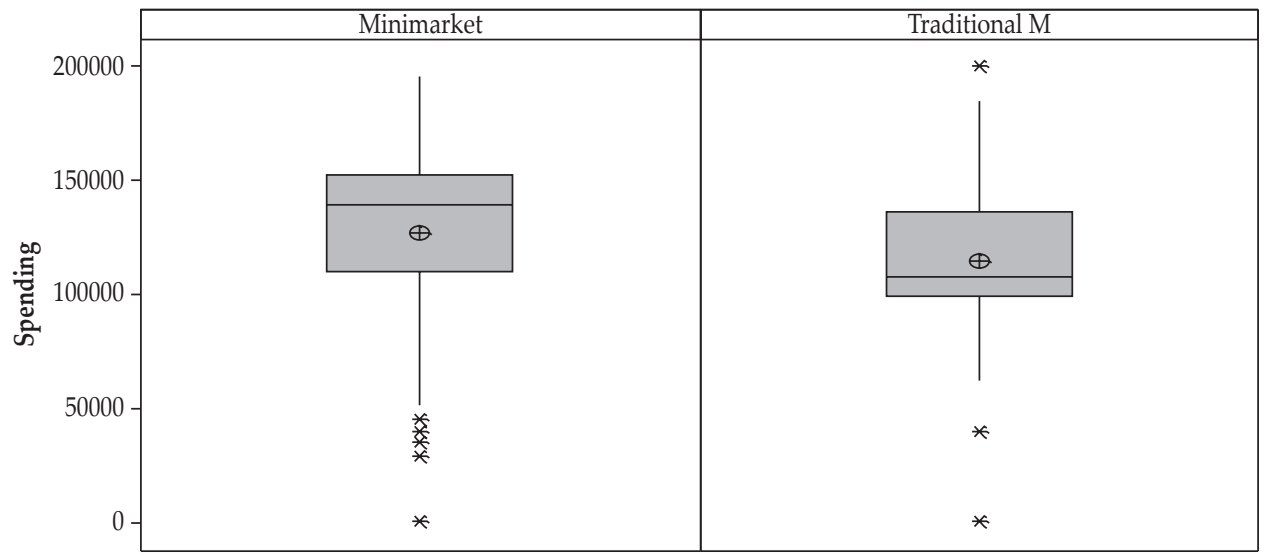

Panel variable: Shopping Center

Source: Juanda (2015)

Figure 10. Confidence Level and Shopping Boxplot of Shopping for 80 Consumers at Minimarkets and 40 Consumers at Traditional Markets 


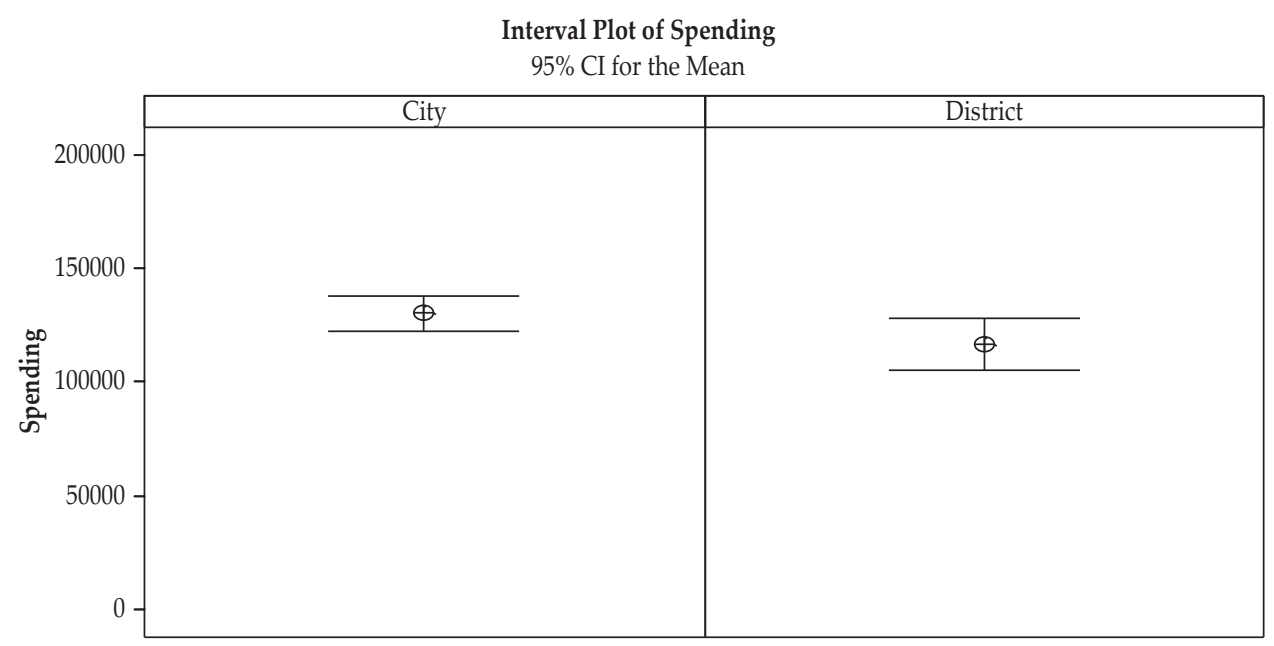

Panel variable: Recidence

Source: Juanda (2015)

Boxplot of Spending

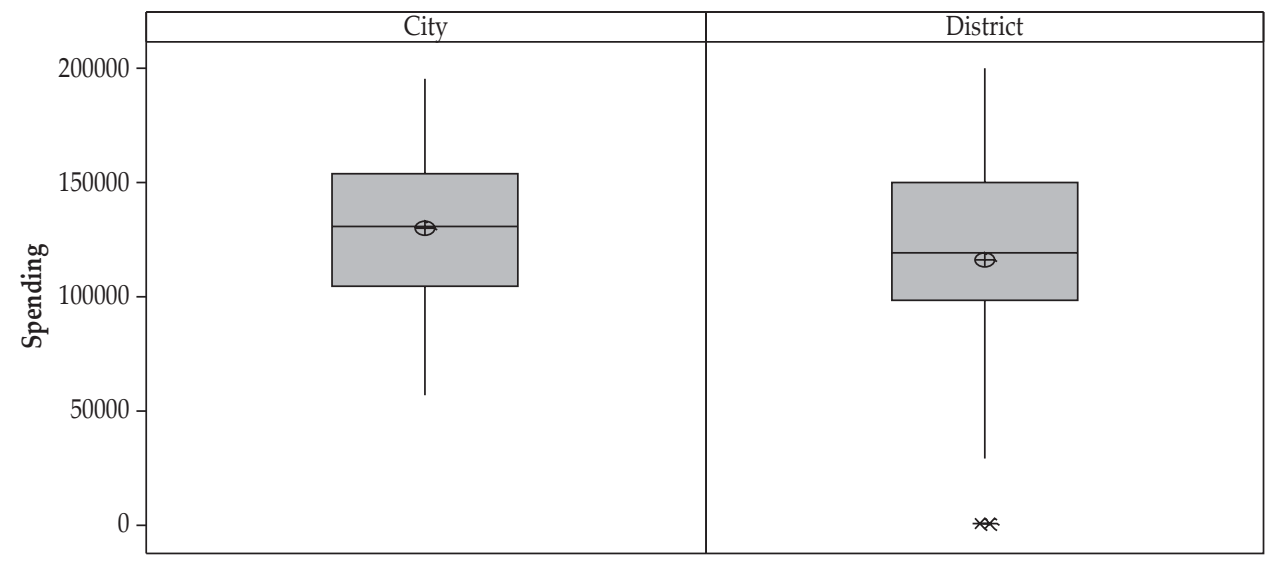

Panel variable: Recidence

Source: Juanda (2015)

Figure 11. Confidence Level and Shopping Boxplot of 55 Consumers Living in the District and 65 Consumers Living in the City 
Based on the ANCOVA results in Table 2, the influence of the denomination (F1) on spending depends on the type of shopping places (F5) with a p-value = 0.058. In Figure 12, it appears that for Minimarket, the average consumer spending is higher when using large denominations (IDR 135,290) than that of using small denominations (IDR 119,040). The consumers feel that 1 banknote of IDR 200,000 is easier or more practical in spending on various needed goods through a single payment. As for the Traditional Market, the average consumer spending is higher when using small denominations (IDR 120,510) than that of using large denominations (IDR 109,293). Consumers tend to be reluctant about spending a single IDR 200,000 banknote because the trader must provide the changes for each item, especially for relatively low-price items.

Based on Table 2 ANCOVA results, it can be also seen that the influence of the denomination (F1) on spending, other than depending the type of marketplace of shopping (F5), depends on the price of goods (F2) with a p-value $=0,007$. In Figure 13a, it appears that the low-priced goods group has the average consumer spending in Minimarkets which is higher when using large denominations (IDR 136,930) than that of using small denominations (IDR 104,375). The consumers feel that a single IDR 200,000 banknote is more convenient or more practical in spending on various needed goods, through a single payment. While the average consumer spending in the Traditional Market is higher using small denominations (IDR 114,760) than that of using large denominations (IDR 87,315). Consumers tend to be reluctant to spend a single IDR 200,000 banknote because the trader must provide the changes for each goods expenditure, especially the relatively low-price goods.

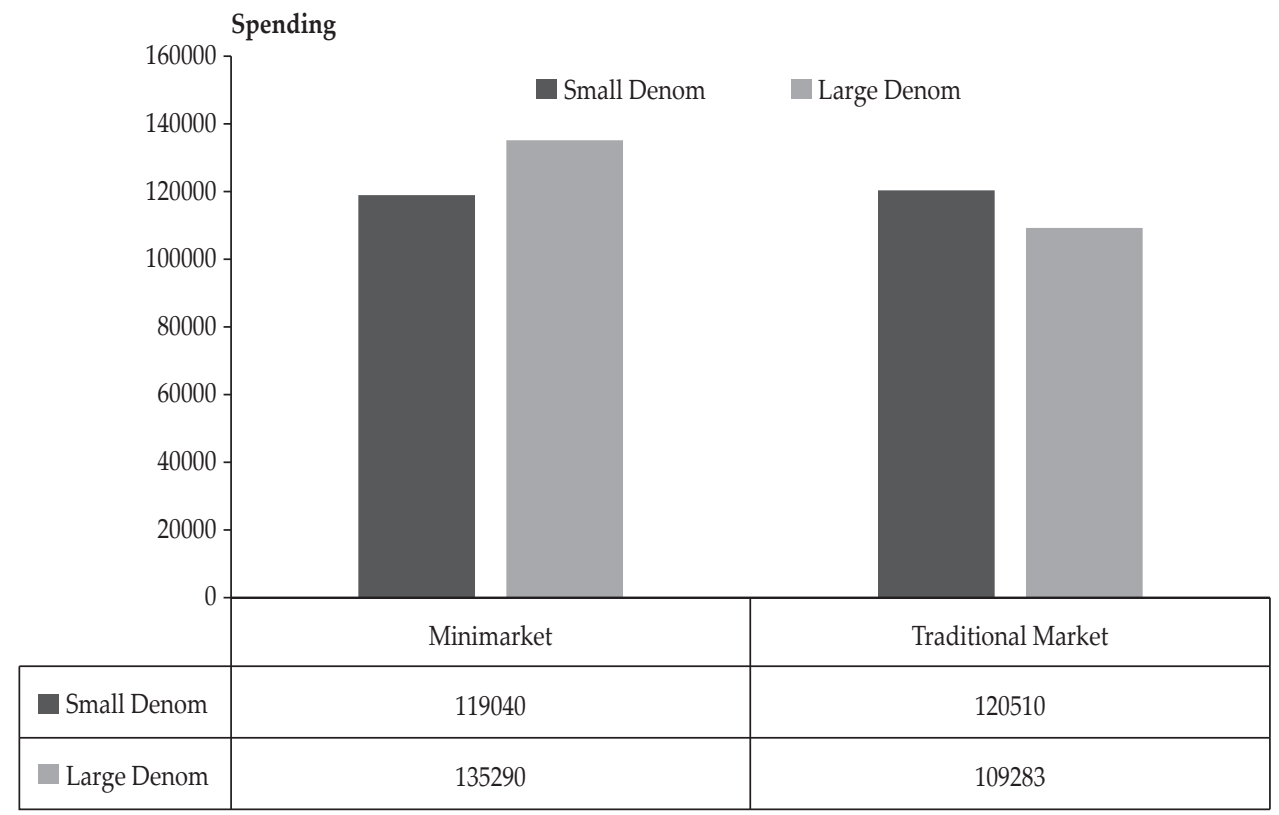

Source: Juanda (2015)

Figure 12. Average Shopping Using Large and Small Denominations at the Minimarkets and Traditional Markets 
(a)

\section{Low price}

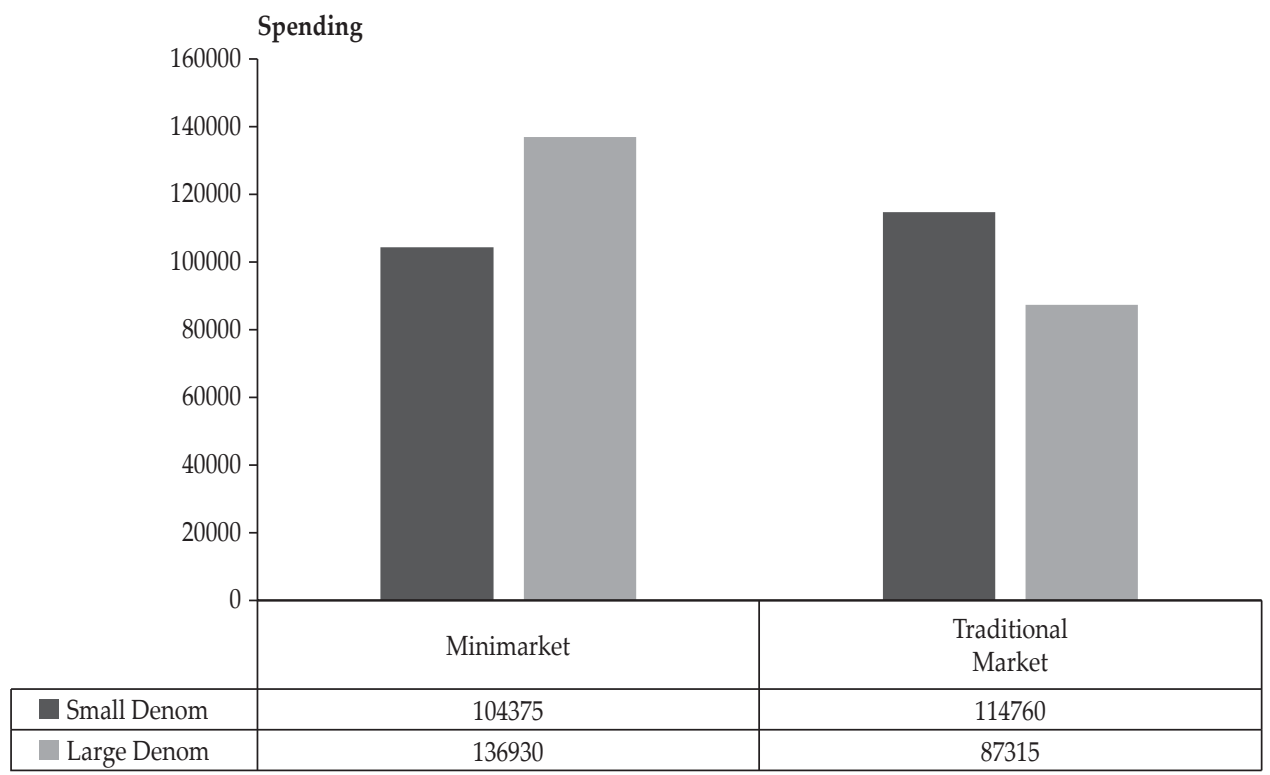

Source: Juanda (2015)

(b)

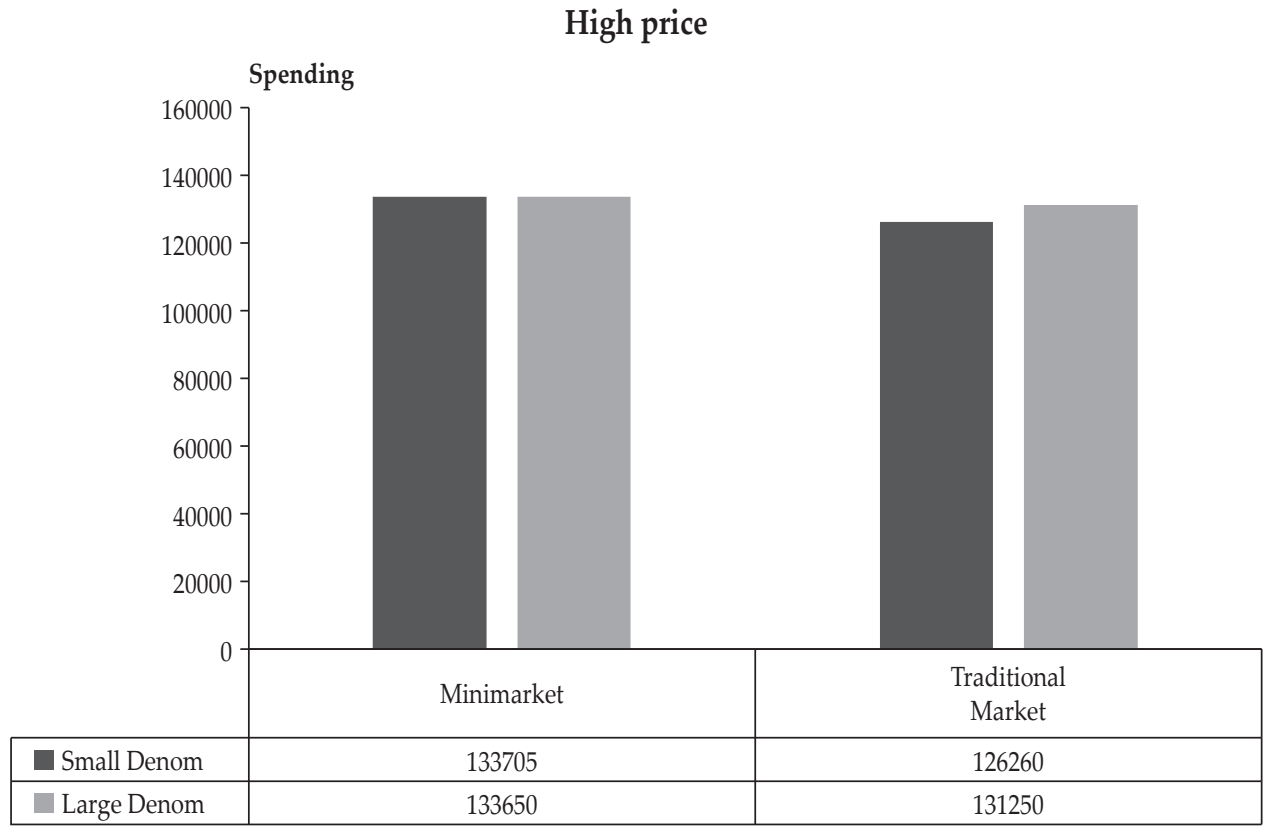

Source: Juanda (2015)

Figure 13. Average Shopping Using Large and Small Denominations for Each Type of Market (Minimarket and Market) by Group of Goods with Different Prices (Low and High) 
As for the high-priced good groups in Figure 13b, it appears that the average consumer spending in Minimarket is "relatively similar" when using either large denominations (IDR 133,650) or small denominations (IDR 133,705). The consumers will try to spend small denominations at a high price (above IDR 100,000/unit), thus, it makes no difference using small or large denominations. While the average consumer spending in the Traditional Market is not so significantly different using large denominations as well as small denominations.

In Figure 14a, it can be seen that consumers who shop at Minimarkets have an average spending on goods at low prices that are higher when using large denominations (IDR 136,930) than the small ones (IDR 104,375). The consumers feel a banknote of IDR 200,000 is simpler or more practical in spending on various needed goods, through a single payment. Meanwhile, the average spending on goods with high prices is "relatively the same" using small denominations (IDR $133,705)$ or larger ones (IDR 133,650). The consumers will try to spend small denominations on high price goods (above IDR 100,000/unit), leading to no differences small or large denominations. While, in Traditional Markets in Figure $14 \mathrm{~b}$, it can be seen that the average goods expenditure with low price is "higher" when using small denomination (IDR 114,760) than larger ones (IDR 87,315). The consumers tend to be reluctant on spending an IDR 200,000 banknote because the merchant must provide the changes for each item, especially the relatively low price (maximum IDR 50,000/unit). In addition, the average spending on goods with high prices (above IDR 100,000/unit) is "higher" when using large denominations (IDR 131,250) than using small ones (IDR 126,260). The consumers feel that an IDR 200,000 banknote is easier or more practical in purchasing the needed goods at high prices. This result is consistent with the output obtained in the laboratory study (Figure 4a). 
(a)

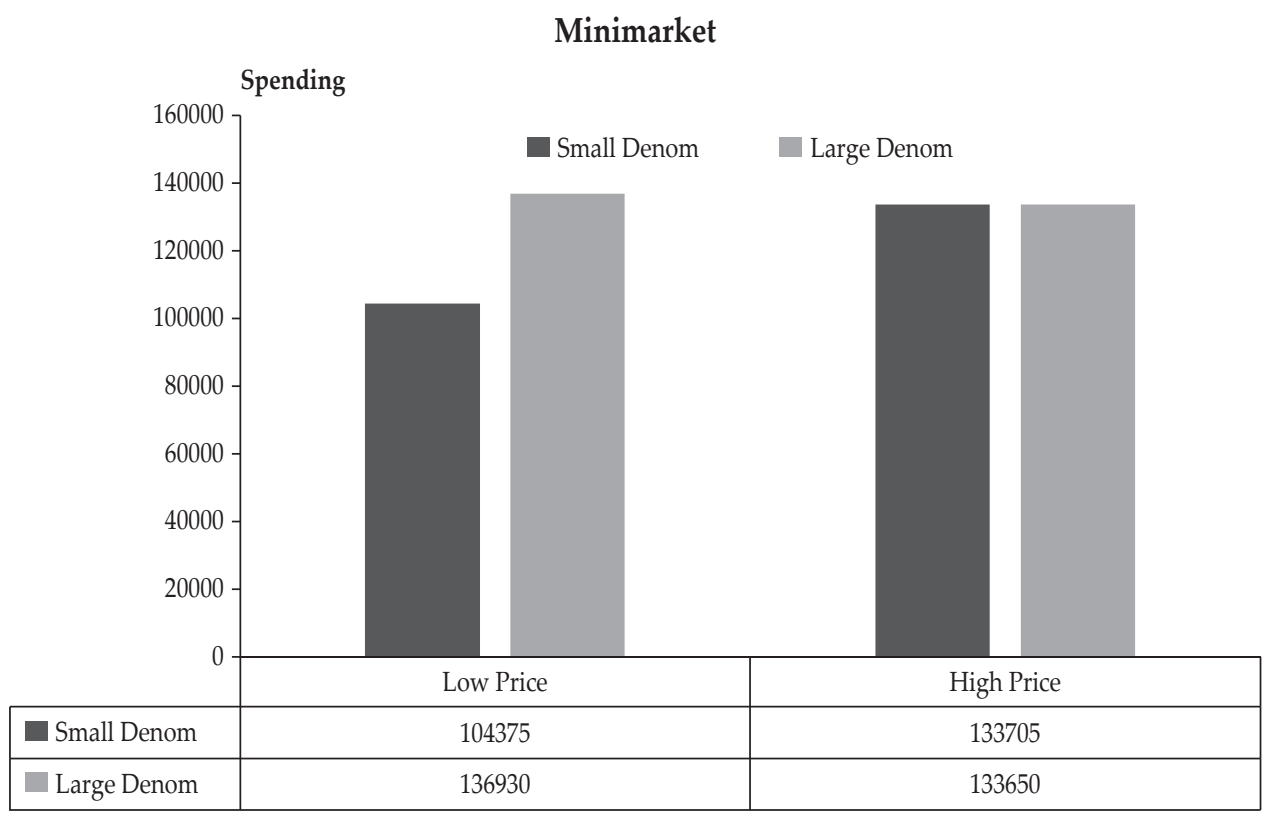

Source: Juanda (2015)

(b)

Traditional Markets

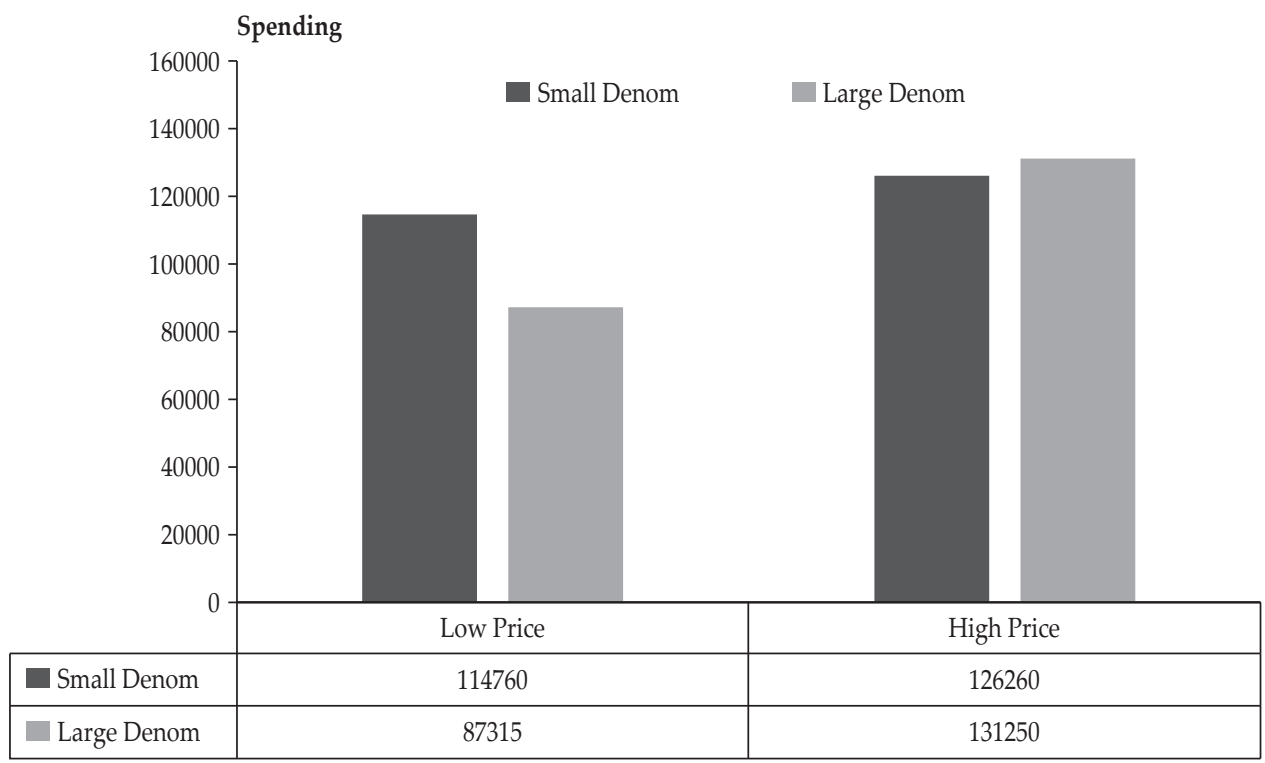

Source: Juanda (2015)

Figure 14. Average Spending of Each Group of Goods at Different Prices (Low and High) Using Different Denominations (Large and Small) Based on the Types of Markets (Minimarket and Market) 
As can be seen in Table 2. of the ANCOVA, the influence of planning (F4) on spending is dependent on market types of the shopping places (F5), with a p-value $=0,005$. Based on Figure 15, it appears that in Minimarket, the average spending is "relatively the same" for consumers who already have planned or not. The consumers feel that using large denominations as well as multiple banknotes of small denominations of the same nominal value (IDR 200,000) makes no difference in terms of spending at the Minimarkets because the availability of needed goods varies somewhat in a place relatively close to purchasing. As for the Traditional Market, the average consumer spending, that has already planned, is higher (IDR 133,050) than the unplanned consumer. The consumers, who have a shopping plan in a traditional market, relatively know to which merchant he is going to buy, while the consumers around the traditional market (without a shopping plan) should find a trader who is widespread in the traditional market to buy the required goods which are relatively reluctant to put all the money (IDR 200,000).

Based on the field study, the majority of the respondents agree with the issuance of IDR 200,000 banknotes because it feels bigger more practical and flexible. However, spending on large denominations is also influenced by the price level and place of purchase. Areas with relatively high price levels, such as in eastern and urban areas, where there are many modern markets, require larger denominations. This is because the use of large denominations is felt more practical. In contrast, regions with relatively low-price levels and districts which are still found in traditional markets, need smaller denominations.

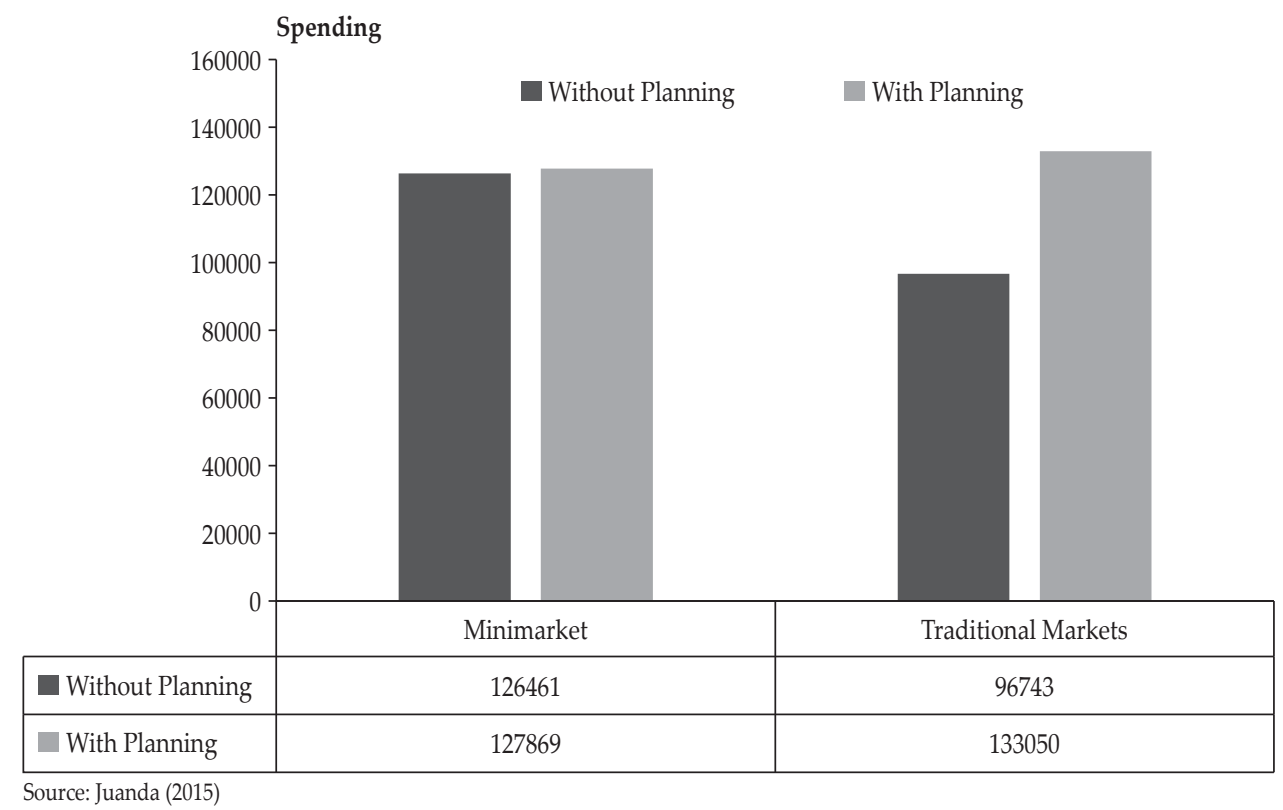

Figure 15. Average Shopping with Planning and without Planning for Each Type of Markets (Minimarket and Traditional Market) 


\section{CONCLUSIONS}

This paper provides several interesting findings, which are consistent across laboratory study and field study:

1. Regardless the consumer characteristic, location, group of good price, and type of market, the total spending using large denomination do not differ significantly than using small denomination.

2. Related to the consumer's self-control, the laboratory study shows it affects the consumer's spending. Consumers with better self-control can manage to spend fewer than those without self-control. The field study shows that consumers in the city, with averagely higher needs, income, and education level, tend to spend more than consumers in village.

3. Related to purchasing plan, this paper find that the average spending of consumer with purchasing plan tend to be higher than those without purchasing plan.

4. Related to goods price, the total spending on high price group product is larger when using large denomination, relative to when using small denomination.

5. Related to market location, in modern market (such as retail minimarket), the total spending is always larger when using large denomination compared to small denomination. This applies both for the group of low and high price goods. The reasons behind this are (i) simplicity and (ii) larger good variation. Furthermore, the total spending of consumer in traditional market is higher when they are planned; while for modern market, the spending plan does not affect the total spending.

These findings lead to the main conclusion of this paper that the denomination will affect the spending across goods price categories, market type, and the absence of purchasing plan. The conclusion implies the possibility to issue the IDR 200,000 in Indonesia. Furthermore, the amount and the distribution of denomination need to address the characteristic of consumer, good prices, and the condition of physical market.

\section{REFERENCES}

Baumeister, F. Roy. (2002). Yielding to Temptation: Self-Control Failure, Impulsive Purchasing, and Consumer Behavior. Journal of Consumer Research, 28(4), p. 670-676.

Olivier Blanchard. (2009 ). Macroeconomics. Fifth Edition. Pearson Prentice Hall. New Jersey.

Chen, N. Chau. (1976). Currency Denominations and the Price Level. Journal of Political Economy, 84(1), p. 179-184.

Gourville, T. John. (1998). Pennies-a-Day: The Effect of Temporal Reframing on Transaction Evaluation. Journal of Consumer Research, 24(4), p. 395-408.

Hoch, J. Steven dan Loewenstein, F. George. (1991). Time-Inconsistent Preferences and Consumer Self-Control. Journal of Consumer Research, 17(4), p.492-507.

James M. Henderson, dan Richard E. Quandt. (1980). Microeconomic Theory: A Mathematical Approach. Third Edition. McGraw-Hill. Singapore. 
Juanda, Bambang, Annazah, S. Nur, Baeti, N. Falikhah. (2017). Analisis Pengaruh Pertumbuhan Ekonomi, Inflasi, Jenis Barang, Jumlah Penghilangan Angka Nol, Masa Transisi dan Tahapan Redenominasi terhadap Kinerja Perekonomian, Mimeo. IPB.

Juanda Bambang. (2017). Ekonomi Eksperimental, Mimeo. IPB.

Juanda, Bambang, Novitasari, Wita, Annazah, S. Nur, Baeti N. Falikhah. (2016). Analisis Pengaruh Denominasi Rp 200.000 dan Rp 500.000, Harga, serta Perencanaan terhadap Belanja dengan Pendekatan Eksperimen, Mimeo. IPB.

Juanda, Bambang. (2015). Laporan Experimental Study: Analisa Kebutuhan Masyarakat akan Rupiah Denominasi Rp 200.000 dan Identifikasi Efek Psikologi yang Timbul (Denomination Effect), Mimeo. Bank Indonesia.

Juanda, Bambang. (2012). Experimental Economics in Indonesia: Lesson Learned and Best Practices, Mimeo. IPB.

Bambang Juanda. (2009). Metodologi Penelitian Ekonomi dan Bisnis. Edisi Kedua. IPB Press. Bogor.

Mishra Himanshu, Mishra Arul, dan Nayakankuppam Dhananjay. (2006). Money: A Bias for the Whole. Journal of Consumer Research, 32(4), p. 541-549.

John Neter, Michael Kutner, Christopher Nachtsheim, William Wasserman. (1996). Applied Linear Statistical Models. Mc Graw-Hill Companies. Inc, New York.

Pambudi, Andika, Juanda, Bambang, Priyarsono S. Domincus. (2014). Penentu Keberhasilan Redenominasi Mata Uang: Pendekatan Historis dan Eksperimental. Buletin Ekonomi Moneter dan Perbankan, 17(2), hal. 167-196.

Raghubir, Priya dan Srivastava, Joydeep. (2009). The Denomination Effect. Journal of Consumer Research, 36(4), p. 701-713.

Smith L. Vernon. (1976). Experimental Economics: Induced Value Theory. The American Economic Review, 66(2), p. 274-279.

Sumarwan, Ujang. (2014). Perilaku Konsumen: Teori dan Penerapannya dalam Pemasaran. Ghalia Indonesia. Bogor. 
This page is intentionally left blank 